\title{
Silencing of TaCKX1 Mediates Expression of Other TaCKX Genes to Increase Yield Parameters in Wheat
}

\author{
Bartosz Jabłoński ${ }^{1}$, Hanna Ogonowska ${ }^{1}$, Karolina Szala ${ }^{1}{ }^{\mathbb{D}}$, Andrzej Bajguz ${ }^{2}{ }^{\mathbb{D}}$, \\ Wacław Orczyk ${ }^{3}$ and Anna Nadolska-Orczyk $1, *$ (D) \\ 1 Department of Functional Genomics, Plant Breeding and Acclimatization Institute-National Research \\ Institute, Radzikow, 05-870 Blonie, Poland; b.jablonski@ihar.edu.pl (B.J.); h.ogonowska@ihar.edu.pl (H.O.); \\ k.szala@ihar.edu.pl (K.S.) \\ 2 Laboratory of Plant Biochemistry, Faculty of Biology, University of Bialystok, Ciolkowskiego 1J, \\ 15-245 Bialystok, Poland; abajguz@uwb.edu.pl \\ 3 Department of Genetic Engineering, Plant Breeding and Acclimatization Institute-National \\ Research Institute, Radzikow, 05-870 Blonie, Poland; w.orczyk@ihar.edu.pl \\ * Correspondence: a.orczyk@ihar.edu.pl
}

Received: 19 June 2020; Accepted: 3 July 2020; Published: 7 July 2020

\begin{abstract}
TaCKX, Triticum aestivum (cytokinin oxidase/dehydrogenase) family genes influence the development of wheat plants by the specific regulation of cytokinin content in different organs. However, their detailed role is not known. The TaCKX1, highly and specifically expressed in developing spikes and in seedling roots, was silenced by RNAi-mediated gene silencing via Agrobacterium tumefaciens and the effect of silencing was investigated in 7 DAP (days after pollination) spikes of $\mathrm{T}_{1}$ and $\mathrm{T}_{2}$ generations. Various levels of TaCKX1 silencing in both generations influence different models of co-expression with other $\mathrm{TaCKX}$ genes and parameters of yield-related traits. Only a high level of silencing in $\mathrm{T}_{2}$ resulted in strong down-regulation of $T a C K X 11$ (3), up-regulation of $T a C K X 2.1$, $2.2,5$, and 9 (10), and a high yielding phenotype. This phenotype is characterized by a higher spike number, grain number, and grain yield, but lower thousand grain weight (TGW). The content of most of cytokinin forms in 7 DAP spikes of silenced $\mathrm{T}_{2}$ lines increased from $23 \%$ to $76 \%$ compared to the non-silenced control. The CKs cross talk with other phytohormones. Each of the tested yield-related traits is regulated by various up- or down-regulated TaCKX genes and phytohormones. The coordinated effect of TaCKX1 silencing on the expression of other TaCKX genes, phytohormone levels in 7 DAP spikes, and yield-related traits in silenced $\mathrm{T}_{2}$ lines is presented.
\end{abstract}

Keywords: wheat; cereals; TaCKX1; TaCKX expression; grain yield; cytokinins; phytohormones; gene silencing; RNAi; wheat spikes

\section{Introduction}

Wheat (Triticum aestivum L.) is the third most economically important crop in the world after corn and rice, and probably the most important in moderate climates. It provides approximately $20 \%$ of human calories and protein [1]. The large genome of this high-yielding species, composed of three (AABBDD) genomes, has been very challenging for improving traits [2]. However, it might be a great reservoir to sustain a further increase of grain productivity [3]. The continuous increase of wheat production is necessary to feed the rapidly growing world population [4]. Biotechnological tools implemented in the process of increasing wheat productivity are expected to be beneficial.

Cytokinins (CKs) are important regulators of plant growth and development, influencing many agriculturally important processes [5]. This regulation might occur at the posttranscriptional and/or posttranslational level [6,7], or by the modulation of context-dependent chromatin accessibility [8]. 
CKs modulate the expression of other genes involved in the control of various processes including meristem activity, hormonal cross talk, nutrient acquisition, and various stress responses [9]. There is growing evidence on their key role in seed yield regulation [10]. In cereals and grasses, an increased content of CKs has been reported to positively affect sink potential in developing grains [11] and maintain leaf chlorophyll status during plant senescence [12] and grain filling [13].

The majority of naturally occurring $\mathrm{CKs}$ in plants belong to isoprenoid cytokinins grouping $N^{6}$-(12-isopentenyl) adenine (iP), trans-zeatin (tZ), cis-zeatin (cZ), and dihydrozeatin (DZ) derived from tRNA degradation or from isopentenylation of free adenine nucleosides catalysed by isopentenyltransferase (IPT) or tRNA-IPT. The second, smaller group comprise N6-aromatic CKs, represented by benzyladenine (BA) [14]. To better characterize their physiological role, CKs are classified into such -base active forms as $\mathrm{tZ}, \mathrm{cZ}$, and iP, translocation forms (nucleosides) as $\mathrm{tZ}$-ribosides (tZR), which exhibit a low level of activity, and sugar conjugates (O-glucosides), which are storage and inactivated forms $[14,15]$.

CKs function as local or long-distance regulatory signals, but the mechanisms of their precise spatial and temporal control are still largely unknown [16]. They are produced in roots as well as in various sites of the aerial part of plants [17]. The level of CKs in respective cells and tissues is dependent on many processes, including biosynthesis, metabolism, activation, transport, and signal transduction. Active CKs can be metabolized via oxidation by cytokinin oxidase/dehydrogenase (CKX) or by activity of glycosyltransferases. Many reports have demonstrated that the irreversible degradation step by the CKX enzyme plays an important role in the regulation of cytokinin level in some cereals, namely maize [18], rice [19], barley [20,21], and wheat [22].

The CKX gene families in plants show different numbers of genes and various expression patterns, which are tissue- and organ-specific, suggesting gene-specific functions. The specificity of expression of $11 \mathrm{TaCKX}$ in developing wheat plants were assigned to four groups: highly specific to leaves, specific to developing spikes and inflorescences, highly specific to roots and expressed through all the organs tested [23]. The TaCKX genes co-operated inside and among organs. Their role in plant productivity has been described in many plants including model plants and some cereals. Knock-out mutation or silencing by RNAi of OsCKX2 in rice significantly increased grain number [19]. The same effect of elevated grain number, spike number, and yield was reported for RNAi-silenced HvCKX1 in barley [20,21,24] and repeated for the same gene under field conditions [25]. Moreover, significantly increased grain number per spike was found as the effect of the TaCKX2.4 gene silencing by RNAi [26]. Knock-out mutation of HvCKX1 by CRISPR/Cas9 editing had a limited effect on yield productivity, however significantly decreased CKX enzyme activity in young spikes and 10-day old roots corresponded to greater root length, numbers of root hairs and increased surface area [27]. In contrast, roots of knock-out mutants of ckx3 were smaller.

The role of other TaCKX genes in wheat was analysed based on natural TaCKX variation. Haplotype variants of TaCKX6a02 and TaCKX6-D1 were related to higher filling rate and grain size $[28,29]$. Quantitative trait locus (QTL) found in recombinant inbred lines containing a higher copy number of TaCKX4 was associated with higher chlorophyll content and grain size [30].

To arrange the numbering of $\mathrm{TaCKX}$ family genes, a new annotation for the first two was suggested by Ogonowska et al. (2019) based on the Ensembl Plants database [31] and phylogenetic analysis. TaCKX6a02 was annotated as TaCKX2.1, TaCKX6-D1 (JQ797673) was annotated as TaCKX2.2 and $T a C K X 2.4$ was annotated as TaCKX2.2. Annotations for these genes were maintained in the recently published review on the TaCKX [22], however tested in this research TaCKX10 was renamed as TaCKX9 and $T a C K X 3$ was renamed as TaCKX11. Newly revised by Chen et al. [22], naming is applied and former names are given in brackets.

Due to the size and complexity of the wheat genomes, the knowledge about the role of $\mathrm{TaCKX}$ genes, containing homologues from three genomes, is more difficult to obtain, because of the limited number of natural mutants. Most homoeologous genes are expected to have overlapping functions [32], therefore the effect of gene mutations might be masked by the other genomes. One solution to silence 
all of them is to apply RNAi-mediated gene silencing, which allows silencing of all the homologues. Moreover, this tool made it possible to obtain a number of lines with different levels of silencing, which in the case of genes coding proteins of key importance for life gave a possibility to regenerate plants for analysis [33]. The introduction of a silencing cassette by stable transformation results in a stable, and inherited to $\mathrm{T}_{4}$, effect of silencing [21,34]. The applicability of Agrobacterium-mediated transformation compared to a biolistic one for gene silencing of the developmentally regulated gene HvCKX10 (2) was proved to be reliable [24].

We present the first report on the role of TaCKX1 in the co-regulation of expression of other TaCKX genes, phytohormone content, and their joint participation in the regulation of yield-related traits in wheat. Various levels of gene silencing in $\mathrm{T}_{1}$ and $\mathrm{T}_{2}$ have been related to different patterns of other TaCKX expression, strongly influencing yield-related traits. Models of regulation of phytohormone levels and phenotypic traits in non-silenced and highly silenced $\mathrm{T}_{2}$ plants by the coordinated expression of TaCKX genes are proposed.

\section{Results}

\subsection{Expression Levels of Silenced TaCKX1 in Segregating $T_{1}$ and $T_{2}$ Plants}

Expression levels of TaCKX1 were measured in 44 segregating $\mathrm{T}_{1}$ plants from $8 \mathrm{~T}_{0} \mathrm{PCR}+$ lines. In $14 \mathrm{~T}_{1}$ plants relative expression (related to the control $=1.00$ ) ranged from 0.39 to 0.88 with the mean of $0.67( \pm 0.14)$. In $30 \mathrm{~T}_{1}$ plants, relative expression ranged from 0.90 to 1.52 with the mean of $1.16( \pm 0.18)$ (Figure 1). The proportion of silenced to non-silenced plants changed in the $\mathrm{T}_{2}$ generation. There were 42 silenced from 0.24 to 0.88 plants with the mean of $0.54( \pm 0.14)$ and 20 non-silenced plants. Eight of them, with low relative expression ranging from 0.24 to 0.40 (mean $0.33 \pm 0.14$ ) and representing different $\mathrm{T}_{1}$ lines, were selected for further analysis.

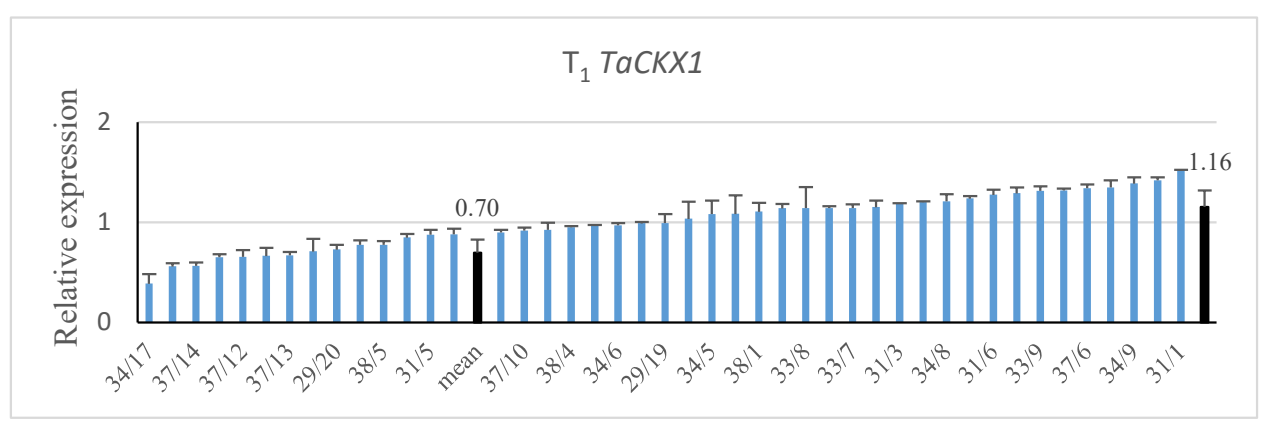

(a)

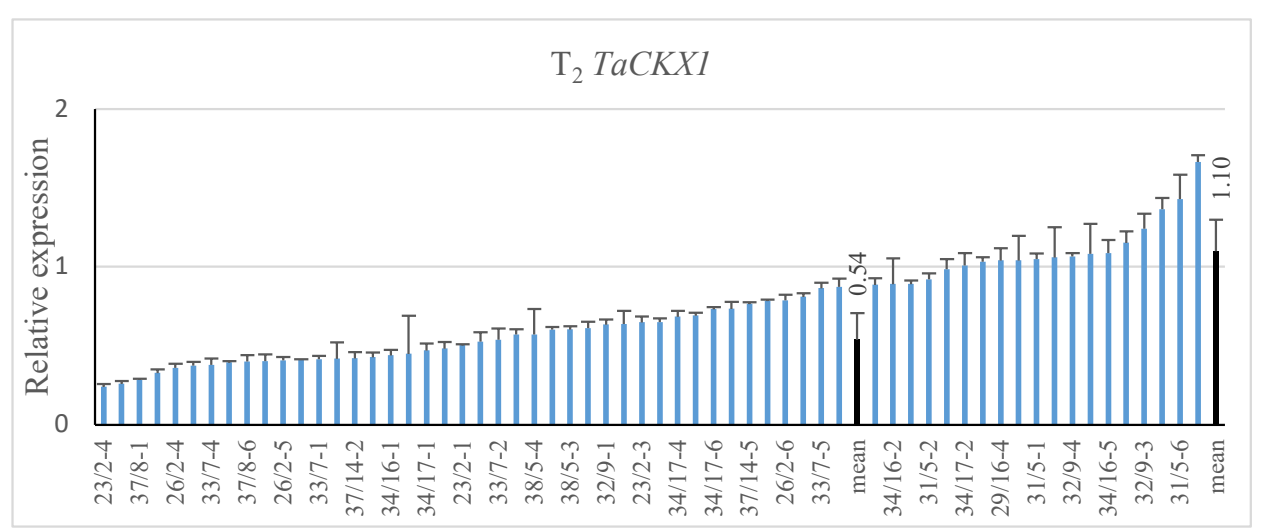

(b)

Figure 1. Relative expression level of silenced TaCKX1 in segregating $\mathrm{T}_{1}(\mathbf{a})$ and $\mathrm{T}_{2}$ (b) plants. The level of expression is related to the control set as 1.00. 


\subsection{Co-Expression of Silenced TaCKX1 with Other TaCKX Genes in $T_{1}$ and $T_{2}$ and $C K X$ Enzyme Activity}

Mean relative expression of TaCKX1 in the selected 8 lines was 0.67 in $\mathrm{T}_{1}$ and was decreased to 0.33 in $\mathrm{T}_{2}$ (Figure 2). Similarly, in the case of TaCKX11 (3) related gene expression was 0.81 in $\mathrm{T}_{1}$ and was decreased to 0.34 in $\mathrm{T}_{2}$. Relative expression levels of TaCKX2.2 and TaCKX9 (10) were decreased in $\mathrm{T}_{1}$ to 0.51 and 0.39 and increased in $\mathrm{T}_{2}$ slightly above the control level, to 1.08 and to 1.10 respectively. Mean relative values for TaCKX2.1 were similar to control in $\mathrm{T}_{1}$ (1.05) and slightly increased in $\mathrm{T}_{2}$ (1.17). Relative expression of $\mathrm{TaCKX} 5$, which was in $\mathrm{T}_{1}$ below the control level (0.84), was significantly increased to 1.82 in $T_{2}$. The relative values of CKX enzyme activity in both generations were around the control, 1.00 .

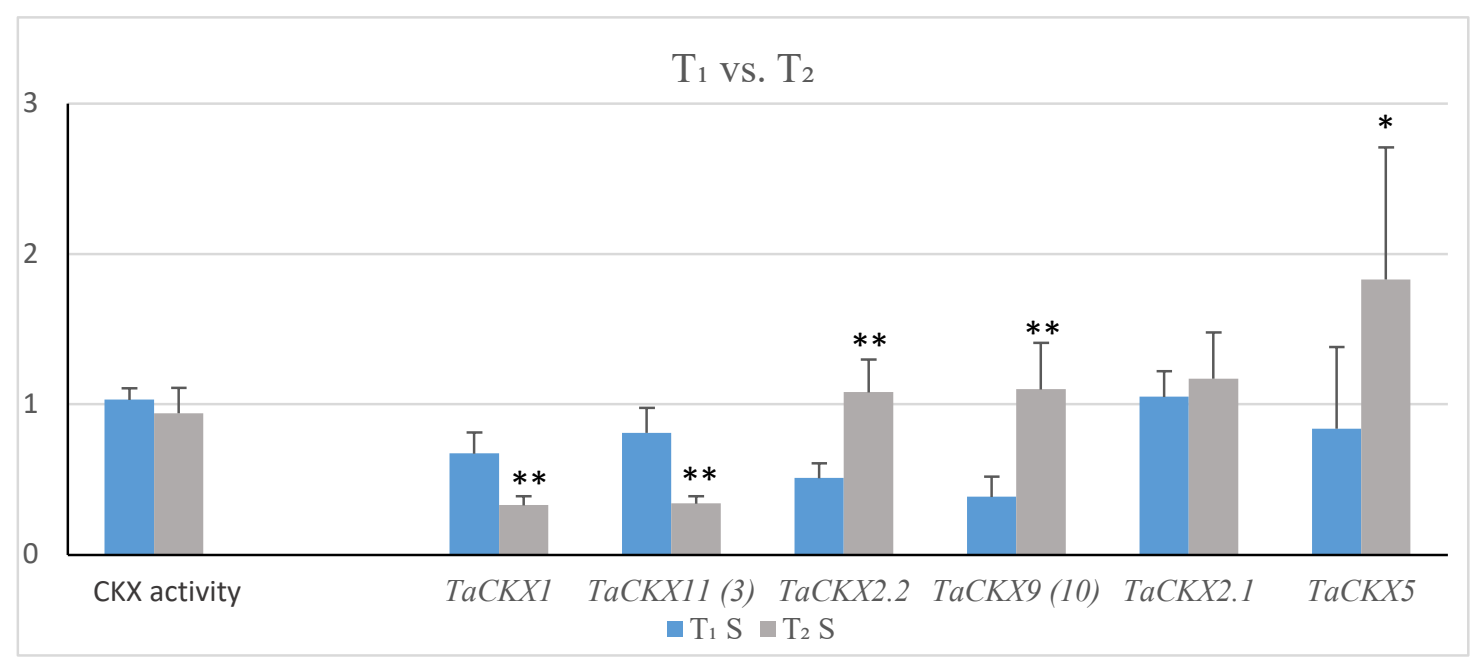

Figure 2. Comparison of means of relative CKX enzyme activity and selected gene expression levels in $\mathrm{T}_{1}$ (bars) and $\mathrm{T}_{2}$ (line) generation of silenced lines. ${ }^{*}$ - significant at $p<0.05$; ${ }^{* *}$ - significant at $p<0.01$.

The effect of TaCKX1 silencing on the levels of expression of selected TaCKX genes is presented by the expression ratio indicator (Table 1), which is a quotient of the mean relative value in silent per mean relative value in non-silent, control plants. In the case of TaCKX1 and TaCKX11 (3), the ratio indicator, significantly decreased in $\mathrm{T}_{1}$, was strongly decreased in $\mathrm{T}_{2}$. The value of the ratio indicator for TaCKX2.2 was not changed in $\mathrm{T}_{1}$ compared to the control and was only slightly decreased in $\mathrm{T}_{2}$. The expression ratio indicator of $\mathrm{TaCKX} 9$ (10), strongly decreased to 0.59 in $\mathrm{T}_{1}$, rose above the control level (1.15) in $\mathrm{T}_{2}$. Already high in $\mathrm{T}_{1}$, the expression ratio indicator for TaCKX2.1 (1.22) increased to 1.32 in $\mathrm{T}_{2}$. The phenotype ratio indicator for CKX enzyme activity was 1.01 in $\mathrm{T}_{1}$ and 0.99 in $\mathrm{T}_{2}$.

Table 1. Effect of TaCKX1 silencing on expression levels of selected TaCKX genes presented by expression ratio indicator (mean value in silent/mean value in non-silent, control plants) in $\mathrm{T}_{1}$ and $\mathrm{T}_{2}$ generations.

\begin{tabular}{cccc}
\hline & $\mathbf{T}_{\mathbf{1}}$ (SD) & $\mathbf{T}_{\mathbf{2}}$ (SD) & Effect of TaCKX1 Silencing $\mathbf{T}_{\mathbf{1}} / \mathbf{T}_{\mathbf{2}}$ \\
\hline $\mathrm{TaCKX1}$ * & $0.58(0.12)$ & $0.28(0.05)$ & decreased/strongly decreased \\
$\mathrm{TaCKX11(3)}$ & $0.80(0.16)$ & $0.36(0.05)$ & decreased/strongly decreased \\
$\mathrm{TaCKX} 2.2$ & $1.08(0.22)$ & $0.98(0.18)$ & slightly increased/similar \\
$\mathrm{TaCKX9(10)}$ & $0.59(0.20)$ & $1.15(0.32)$ & strongly decreased/slightly increased \\
$\mathrm{TaCKX2.1}$ & $1.22(0.19)$ & $1.32(0.35)$ & increased/increased \\
$\mathrm{TaCKX5}$ & $1.00(0.65)$ & $1.08(0.52)$ & the same/similar \\
$\mathrm{CKX}$ activity & $1.01(0.07)$ & $0.99(0.18)$ & the same/the same \\
\hline \multicolumn{5}{c}{ *-significant at $p<0.05}$.
\end{tabular}

In $\mathrm{T}_{1}$ segregating plants, $\mathrm{CKX}$ enzyme activity significantly correlated with spike length ( 0.51 ; $\mathrm{n}=16)$ and grain weight $(0.50 ; \mathrm{n}=16)$, but in $\mathrm{T}_{2}$ these correlations were not significant. 
2.3. Influence of TaCKX1 Silencing on Phenotypic Traits and Chlorophyll Content in Flag Leaves of $T_{1}$ and $\mathrm{T}_{2}$ Plants

The values of phenotypic traits in $\mathrm{T}_{1}$ plants with slightly decreased relative expression of TaCKX1 $(0.67 \pm 0.14)$ compared to control plants (1.00) were on the same level in the case of plant height and lower for number of spikes, spike length, grain number, and grain yield (Supplementary Table S2). Higher values were obtained for TGW. Data for chlorophyll content measured by SPAD in the flag leaves of first spikes and the next spikes were similar. All these differences were not significant. Opposite results were obtained for some traits in $\mathrm{T}_{2}$ plants with highly silent TaCKX1 $(0.33 \pm 0.06)$ compared to the control (1.00) (Supplementary Table S3). Silent $\mathrm{T}_{2}$ plants were substantially smaller, had a higher number of spikes, number of grains, grain yield, seedling root weight, and lower SPAD values for the flag leaves of first spikes. TGW and spike length were significantly lower than in control plants.

These differences between the slightly silenced $T_{1}$ and highly silent $T_{2}$ generation are expressed by comparison of ratio indicators of phenotypic traits in both generations (Figure 3). There were no changes in plant height, TGW or spike length in $\mathrm{T}_{1}$ plants compared to the control. However, these values were respectively $7 \%, 10 \%$, and $25 \%$ lower in $\mathrm{T}_{2}$ plants. Opposite phenotype ratio indicators for number of spikes per plant and number of grains per plant were about $21 \%$ and $30 \%$ lower in $\mathrm{T}_{1}$ and $57 \%$ and $29 \%$ higher in $\mathrm{T}_{2}$. These differences for spike number, grain number, and TGW were significant.

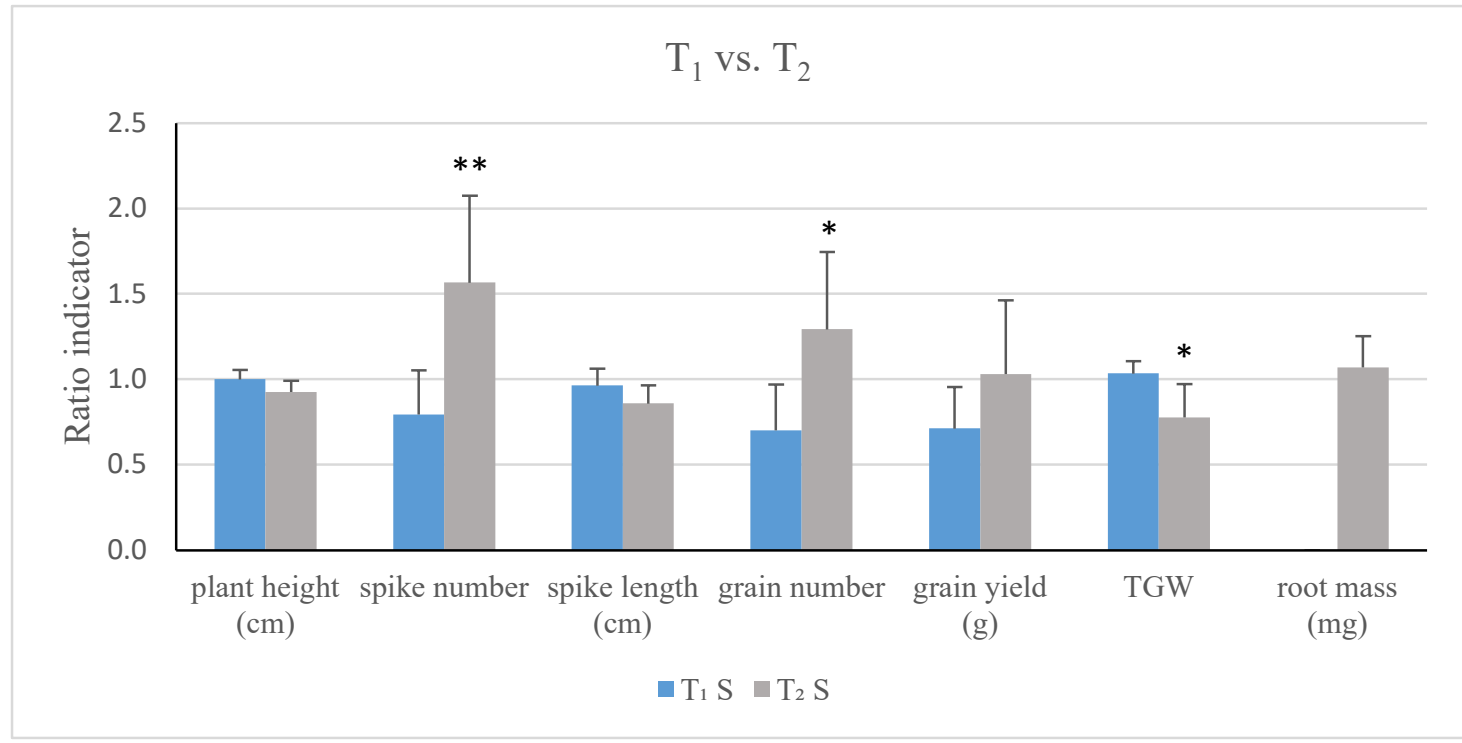

Figure 3. Comparison of phenotypic effect of silencing of TaCKX1 in $\mathrm{T}_{1}$ and $\mathrm{T}_{2}$ generations based on ratio indicators. ${ }^{*}$ - significant at $p<0.05 ;{ }^{* *}$ — significant at $p<0.01$.

The levels of expression of TaCKX1 in 7 DAP spikes of all $\mathrm{T}_{1}$ significantly correlated with number of grains, grain weight, spike length and spike number $(0.47,0.39,0.42$ and 0.33 respectively; $\mathrm{n}=42)$ and grain weight correlated with enzyme activity $(0.33 ; \mathrm{n}=42)$. The TaCKX9 (10) expression level significantly correlated with grain number $(0.51 ; \mathrm{n}=16)$.

Correlation coefficients among the expression of all tested TaCKX genes and enzyme activity, and phenotypic traits in non-silent and highly silent $T_{2}$ are included in Supplementary Table S4A,B. All these correlations are graphically presented in Figures and described in Section 2.6.

\subsection{Phytohormone Content in 7 DAP Spikes of $T_{2}$}

tZGs, which were mainly composed of tZ9G, tZ7G, tZOG and tZ9GOG, were the most abundant cytokinin group in 7 DAP spikes (Figure 4a). Their mean content in control plants was $6.97 \mathrm{ng} / \mathrm{g}$ 
biomass and in silent $T_{2}$ was $6.24 \mathrm{ng} / \mathrm{g}$ biomass respectively. The second most abundant was $\mathrm{tZ}$ with the level of $3.74 \mathrm{ng} / \mathrm{g}$ biomass in the control and $4.59 \mathrm{ng} / \mathrm{g}$ biomass in silent $\mathrm{T}_{2}$. The content of $\mathrm{cZ}$ was slightly lower to $\mathrm{tZ}(2.90 \mathrm{ng} / \mathrm{g}$ biomass) in control but higher $(5.10 \mathrm{ng} / \mathrm{g}$ biomass) in silent plants. CZOG was more abundant in the control than the groups of silent plants, and the content was 1.27 and $0.57 \mathrm{ng} / \mathrm{g}$ biomass respectively. The concentration of DZGs (sum of DZ7G, DZOG, DZ9G and DZOGR) was higher in silent (1.61 ng/g biomass) than in control plants (1.11 ng/g biomass). Low concentrations (below $0.5 \mathrm{ng} / \mathrm{g}$ biomass) were measured for iP and BA. The concentration of IAA was also low and on a comparable level in control and in silent plants $(0.23$ and $0.24 \mathrm{ng} / \mathrm{g}$ biomass respectively). In the case of ABA, the concentration in the control was slightly decreased in silent plants ( 2.61 and $2.29 \mathrm{ng} / \mathrm{g}$ biomass respectively). The concentration of GA was increased from $0.28 \mathrm{ng} / \mathrm{g}$ biomass in the control to $2.93 \mathrm{ng} / \mathrm{g}$ biomass in silent plants, which was more than a 10-fold increase.

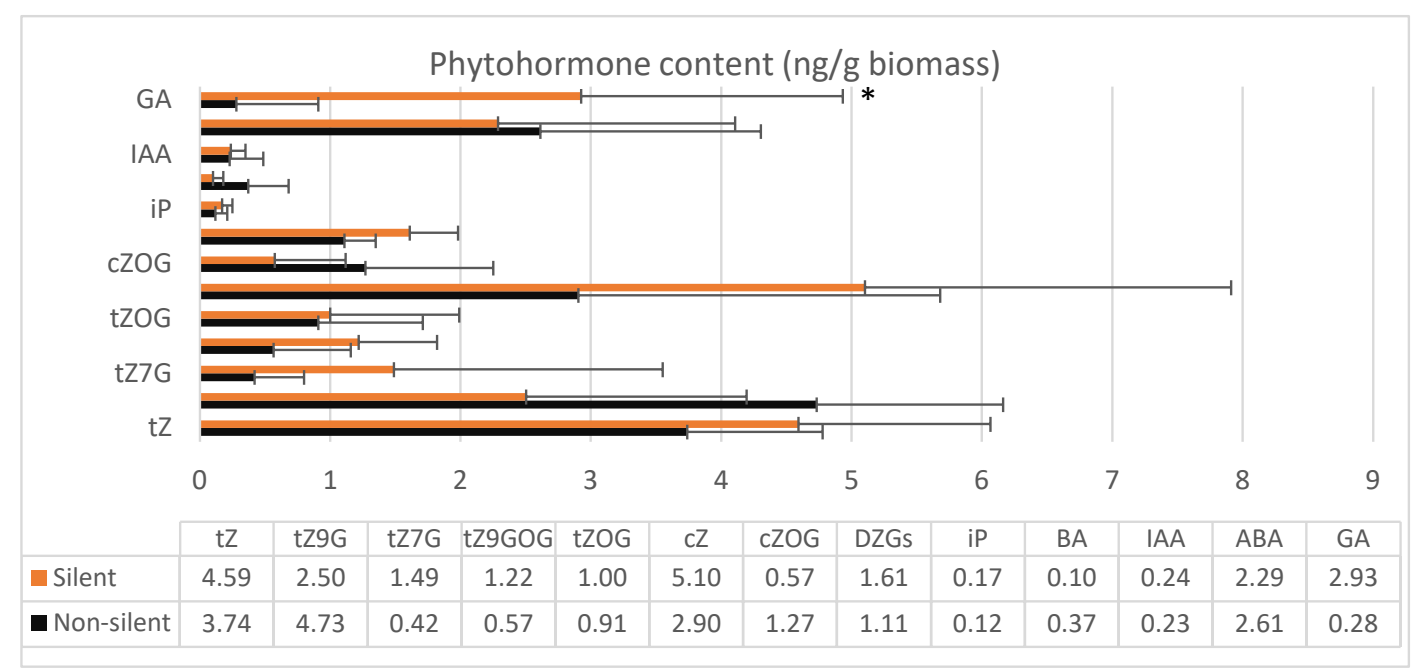

(a)

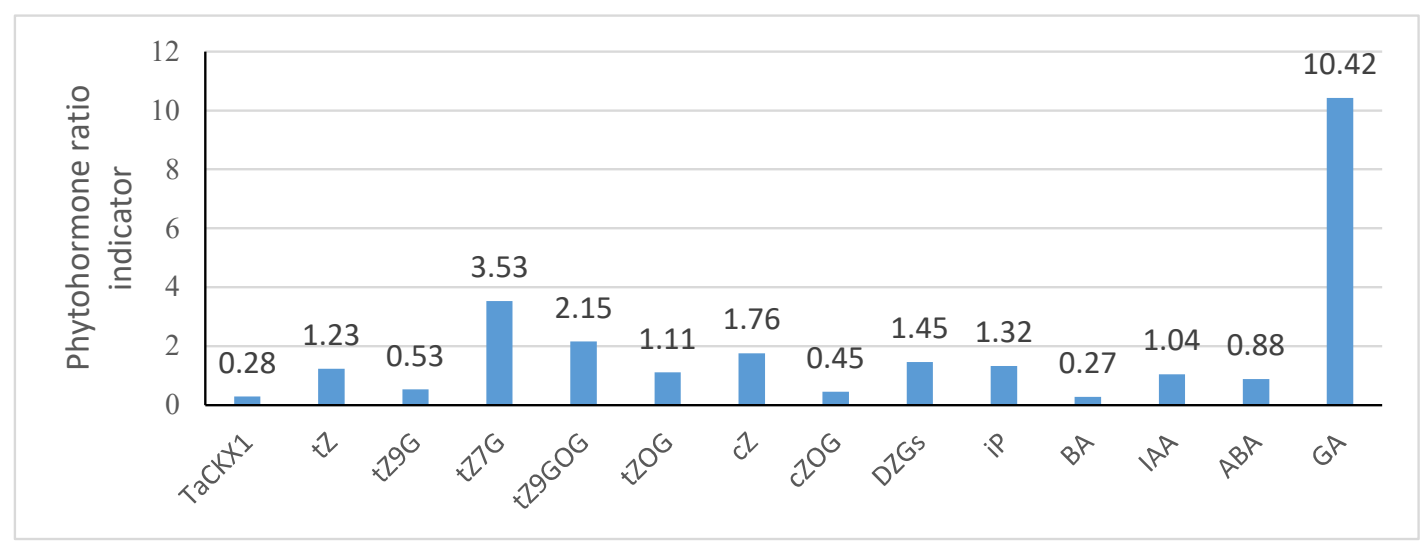

(b)

Figure 4. Phytohormone content (ng/g biomass) measured in the group of control and silent $\mathrm{T}_{2}$ plants (a). Phytohormone ratio indicators (mean value in silent per mean value in not silent, control plants) in silent $\mathrm{T}_{2}$ plants $(\mathbf{b}) .{ }^{*}$ - significant at $p<0.05$. Small amounts $(\leq 1.00 \mathrm{ng} / \mathrm{g}$ biomass): $\mathrm{tZR}, \mathrm{tZOGR}$, cZOGR, DZOG, DZ7G, DZ9G, DZOGR, iP, iP7G, BA, IAA. Trace amounts ( $\leq 0.05 \mathrm{ng} / \mathrm{g}$ biomass) or not detected: cZ9G, cZR, DZ, DZR, iPR, IBA, IPA, NAA, PAA.

Most of the phytohormone ratio indicators in the group of six silent $\mathrm{T}_{2}$ plants (Figure $4 \mathrm{~b}$ ) were much higher than in control plants. There were the following cytokinins: tZ (1.23), tZ7G (3.53), tZ9GOG (2.15), tZOG (1.11), cZ (1.76), sum of DZGs (1.45) and iP (1.32). The ratio indicators for some of them 
were significantly lower, as in the case of BA (0.27), cZOG (0.45) and tZ9G (0.53). Similar values were observed for IAA (1.04), and slightly lower for ABA (0.88), but much higher for GA (10.42).

2.5. Coordinated Effect of TaCKX1 Silencing on Expression of Other TaCKX Genes and Phytohormone Level in 7 DAP Spikes as Well as Phenotype in $T_{2}$

A graphic presentation of the coordinated effect of TaCKX1 silencing on expression of other TaCKX genes and phytohormone levels in $7 \mathrm{DAP}$ spikes as well as the phenotype of $\mathrm{T}_{2}$ plants is presented in Figure 5. The significant decrease of expression of TaCKX1 was coordinated with the significant decrease of TaCKX11 (3), which presumably resulted in a significant increase of most CKs: tZ, tZGs, cZ, DZGs, iP, as well as GA. The increased phytohormone level in the first 7 DAP spikes positively influenced traits such as spike number and grain number, reaching the ratio indicators 1.57 and 1.29, respectively, and negatively influenced TGW (0.78), spike length (0.86), plant height (0.93), and flag leaf senescence (0.95). Opposing data were obtained for TaCKX2.1 and TaCKX9 (10), which showed increased expression in silenced 7 DAP spikes (1.32 and 1.15 respectively). This might have influenced the decreased ratio indicators for phytohormones-cZOG (0.45), BA (0.27), and ABA content (0.88), and slightly increased ratio indicators for yield-related traits: root weight and grain yield (1.07 and 1.03 respectively). Expression ratio indicators for TaCKX5 and TaCKX2.2 were both close to 1.00, but their expression significantly increased compared to $\mathrm{T}_{1}$ and positively correlated with the expression of TaCKX2.1 and TaCKX9 (10) respectively.

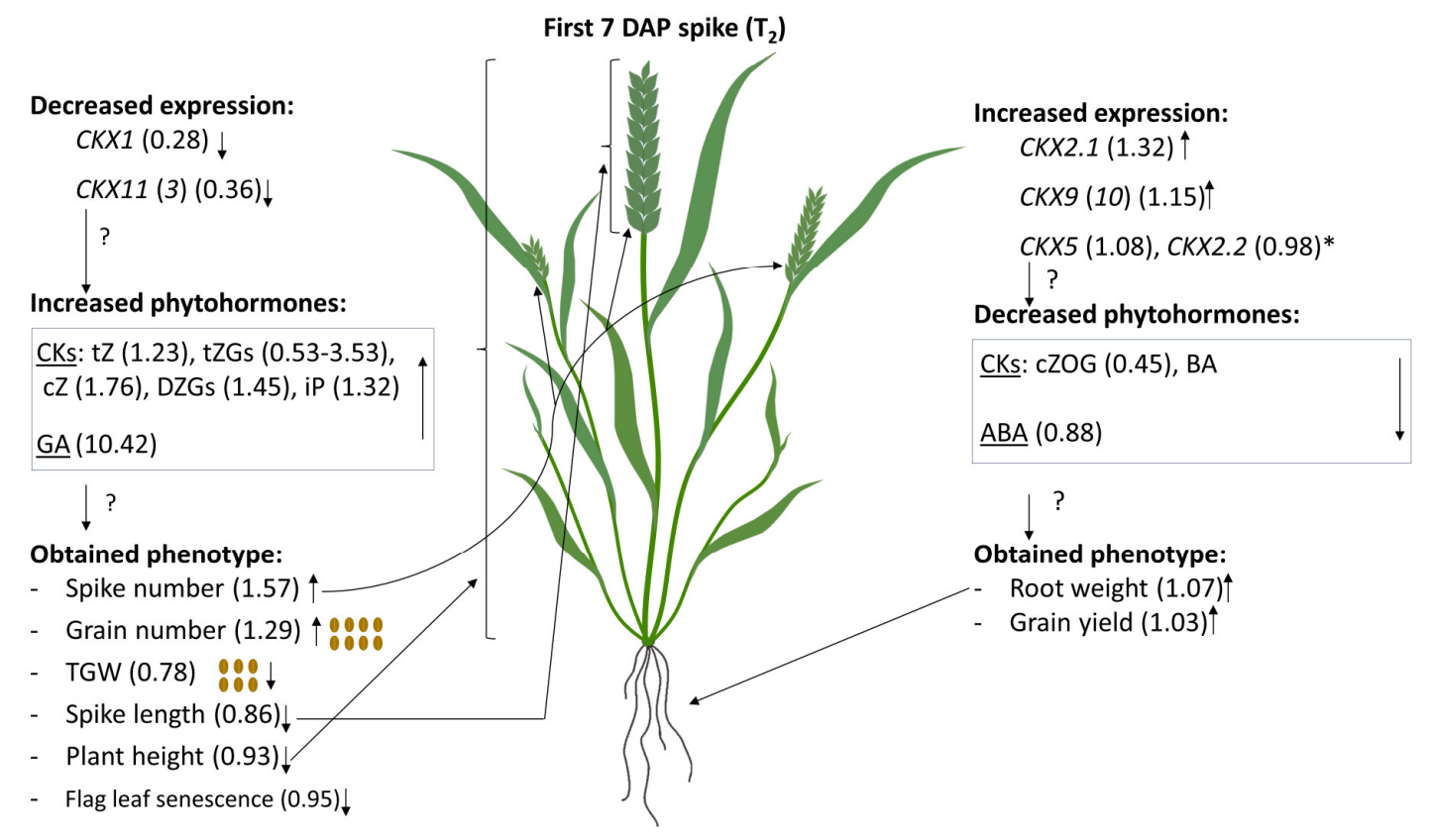

Figure 5. Graphic presentation of coordinated effect of TaCKX1 silencing on expression of other TaCKX genes, phytohormone levels as well as phenotype in $7 \mathrm{DAP}$ spikes of $\mathrm{T}_{2}$ plants based on ratio indicators. *-significantly increased comparing to $\mathrm{T}_{1} ;$ ? - expected changes.

2.6. Models of Co-Regulation of Phytohormone Levels and Phenotype Traits by Coordinated Expression of TaCKX Genes in Non-Silenced and Silenced $T_{2}$ Plants

Two different models of co-regulation of TaCKX expression, phytohormone levels and phenotypic traits in non- silenced and silenced plants of the $T_{2}$ generation are proposed (Figure $6 a-h$ ) based on correlation coefficients (Table S4A,B). 


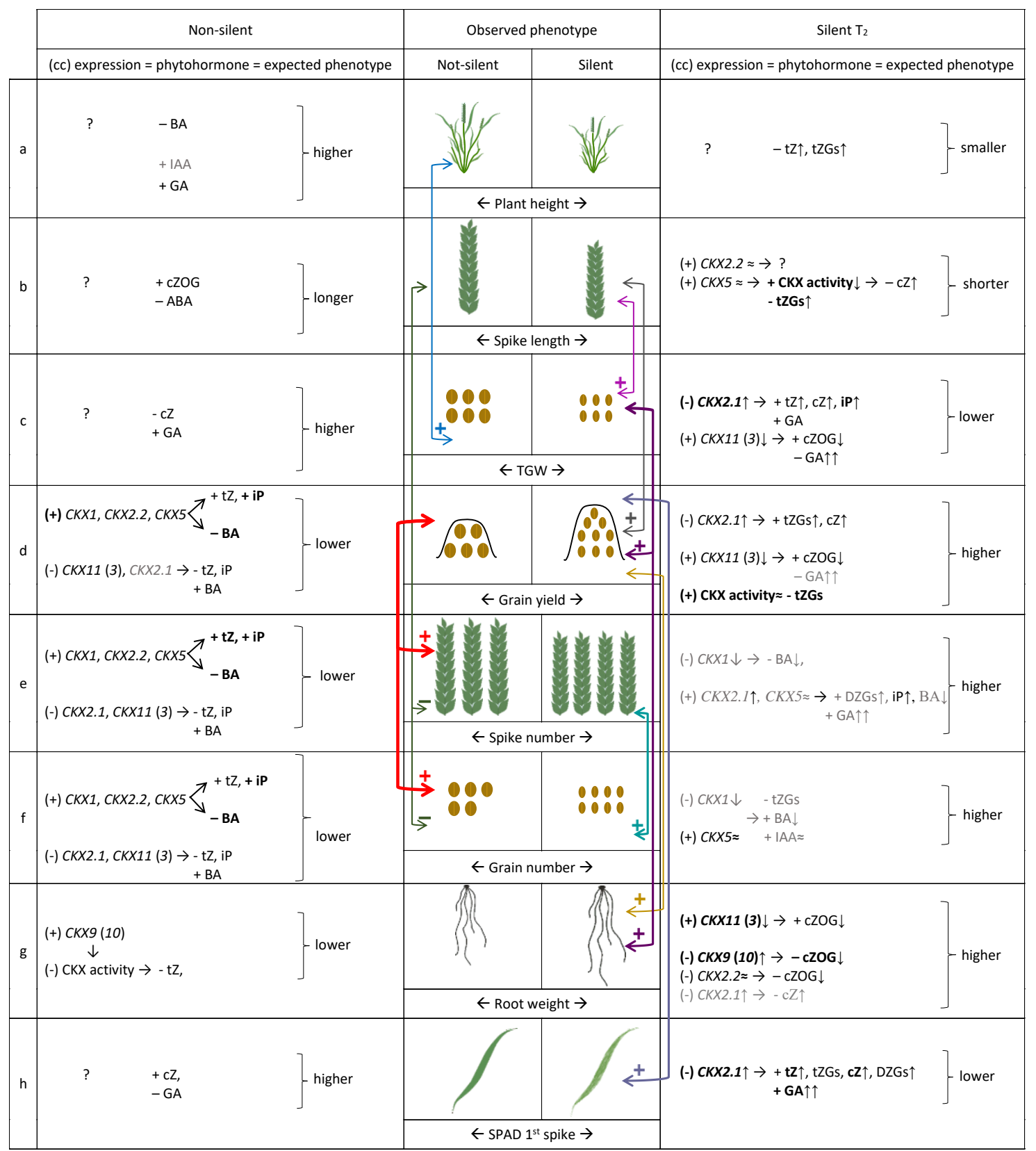

Figure 6. Models of regulation of phytohormone levels and phenotypic traits by coordinated expression of TaCKX genes based on correlation coefficients (cc) in non-silenced and silenced wheat plants (a-h). (cc) - correlation coefficient between expression and trait; (?) - lack of correlation with expression of any gene; bold—strong, significant correlations at $p \leq 0.05$ (cc above 0.82 ); grey-cc from 0.5 to 0.6 .

Plant height (Figure 6a). There was no correlation between plant height and expression values of any TaCKX expressed in 7 DAP spikes of non-silent as well as silent plants. In the first group of plants this trait negatively correlated with BA and positively with IAA and GA content. By contrast, in silent plants the values of plant height were negatively correlated with growing concentration of $t Z$ and $t Z G s$, which resulted in a smaller plant phenotype.

Spike length (Figure 6b) in non-silent plants was positively correlated with BA, and negatively with $\mathrm{cZ}$ and $\mathrm{ABA}$ content. These correlations determined longer spikes and the trait negatively correlated with spike number and grain number. A strong positive correlation between CKX activity and spike length was noted in silent plants. The values of enzyme activity correlated positively with 
slightly increased TaCKX5 expression, which negatively correlated with increasing content of $\mathrm{cZ}$ and tZGs. Spike length in silent plants was positively correlated with grain yield.

TGW (Figure 6c). There was no correlation of TGW with expression of any TaCKX expressed in 7 DAP spikes of non-silent plants. However, the trait was strongly negatively correlated with cZ content and positively with GA. The grains in this group of plants were larger and TGW higher. By contrast, in silent plants there was a strong negative correlation of the trait with growing expression of $T a C K X 2.1$, which positively regulated $\mathrm{tZ}, \mathrm{cZ}$, iP, and GA content. Moreover, the values of expression of down-regulated TaCKX11 (3) positively correlated with decreasing content of cZOG, negatively with highly growing GA and positively with the trait. Altogether it resulted in lower TGW compared to non-silenced plants. The trait in silent plants was strongly and positively correlated with grain yield (0.82) and root weight (0.77).

Grain yield (Figure 6d). Expression levels of TaCKX1, TaCKX2.2 and TaCKX5 in non-silent plants positively correlated with $\mathrm{tZ}$ and $\mathrm{P}$ and negatively with BA content. However, expression of TaCKX11 (3) and TaCKX2.1 regulates the same CKs in opposite way. Altogether, it resulted in lower grain yield comparing to silenced plants, and the trait was strongly positively correlated with spike number (0.93) and grain number (0.99). The increasing expression of TaCKX2.1 positively correlated with a growing content of tZGs and $\mathrm{CZ}$ and negatively with the trait in silent plants. Decreasing expression of TaCKX11 (3), which was positively correlated with decreased cZOG content and negatively with GA content, positively correlated with the trait. A positive correlation was observed between CKX activity and grain yield in this group of plants, which was higher than in non-silent plants. Moreover, CKX activity negatively correlated with tZGs. The trait was strongly correlated with TGW (0.82) and root weight (0.66).

Spike number (Figure 6e) and grain number (Figure 6f) in non-silenced plants were positively regulated by TaCKX1, TaCKX2.2 and TaCKX5, and their expression was positively correlated with $\mathrm{tZ}$, iP and negatively with BA. On the other hand, expression levels of TaCKX2.1 plus TaCKX11 (3) were negatively correlated with the traits as well as with $\mathrm{tZ}$, iP and positively with BA. Both groups of genes finally affected lower spike and grain numbers in non-silent plants in comparison to silent plants and were strongly and positively correlated with each other (0.91) and grain yield (0.93 and 0.99 respectively). In silent plants decreasing expression of $T a C K X 1$ is negatively correlated with both spike and grain number and the gene negatively regulates decreasing BA content. In the case of grain number, the main player positively correlated with the trait is TaCKX5, increased expression of which was correlated with slightly higher IAA content, which resulted in higher grain number. Spike number is also positively regulated by TaCKX5 co-expressed with TaCKX2.1, and both genes were positively correlated with growing CKs, DZGs and iP as well as GA, determining higher spike number. Both traits are highly correlated (0.88) with each other.

Seedling root weight (Figure $6 \mathrm{~g}$ ). There was strong, positive correlation between TaCKX9 (10) expression in 7 DAP spikes and seedling root weight in non-silenced plants. Moreover, CKX activity negatively correlated with $\mathrm{tZ}$ (in spikes) and the trait, which finally resulted in lower root weight. The decreasing expression of TaCKX11 (3) in the case of silent plants was positively correlated with decreasing content of CZOG and strongly positively correlated with the trait. Increasing expression levels of TaCKX9 (10) plus TaCKX2.2 negatively correlated with decreasing content of cZOG and root weight.

Chlorophyll content measured by SPAD in flag leaves of first spikes (Figure 6h). There was no correlation between expression level of any $\mathrm{TaCKX}$ measured in 7 DAP spikes of non-silent plants and the trait. The only correlations were between phytohormone content and the trait, positive for $\mathrm{CZ}$ and negative for GA, which resulted in higher SPAD values (chlorophyll content). Increasing expression of $\mathrm{TaCKX} 2.1$ was strongly positively correlated with growing values of $\mathrm{tZ}, \mathrm{tZGs}, \mathrm{cZ}$, and DZGs as well as GA in silent plants. A strong negative correlation was observed between the gene expression and chlorophyll content, which means that increasing expression of TaCKX2.1 in 7 DAP spikes results in lower chlorophyll content in silent plants. 


\section{Discussion}

First, 7 DAP spike was chosen as a research objective in wheat since decreased HvCKX1 expression at this stage in barley resulted in higher yield due to the higher spike and grain number $[20,21]$. The TaCKX1 gene is an orthologue of $\mathrm{HvCKX1}$ and both genes are specifically expressed in developing spikes [23], indicating their possibly important role in the regulation of yield-related traits. The samples were taken from the middle part of the spikes, when anthesis starts, in order to ensure a similar developmental stage of spikelets for research. The 7 DAP spikes of wheat represent the middle of cell division/cell expansion stage [35,36].

\subsection{Various Levels of TaCKX1 Silencing Influence Different Models of Co-Expression with Other TaCKX Genes and Parameters of Yield-Related Traits}

Various levels of silencing of TaCKX1 in $\mathrm{T}_{1}$ and $\mathrm{T}_{2}$ generate different results of co-expression with other TaCKX genes and plant phenotype. For example, the expression of TaCKX9 (10) was highly and significantly correlated with $T a C K X 1$ only in $\mathrm{T}_{1}$. However, a new and strong positive correlation between TaCKX9 (10) and TaCKX2.2 in highly silenced $\mathrm{T}_{2}$ was observed. Slightly decreased co-expression of silenced TaCKX1 together with TaCKX11 (3) in $\mathrm{T}_{1}$ was much stronger in $\mathrm{T}_{2}$, indicating their positive co-regulation. It should be underlined that there is no homology between the sequence of TaCKX1 used for silencing and sequences of other TaCKX genes tested. Therefore, the process of RNAi silencing was specifically addressed to TaCKX1 silencing. It indicates that the level of silencing of the modified gene affected variable levels of expression of the other TaCKX genes in a co-operative process maintaining homeostasis of CKX enzyme in the research object. The models of co-regulation of other $C K X$ by highly silenced TaCKX1 and knock-out $H v C K X 1$ [27] differ between these species.

The differences in the levels of expression of TaCKX1 and various co-expression of other TaCKX genes in $T_{1}$ and $T_{2}$ resulted in opposite phenotypic effects. Since spike number, grain number, and grain yield were reduced in $\mathrm{T}_{1}$, the same yield-related traits were significantly higher in highly silenced $\mathrm{T}_{2}$ plants. High-yielding phenotype occurred when highly silenced TaCKX1 co-operated with down-regulated TaCKX11 (3) but up-regulated TaCKX5, TaCKX2.2, TaCKX2.1, and TaCKX9 (10). These differences showed that both levels of silencing might be helpful to better understand the function of developmentally regulated genes. Unexpectedly, changes in the expression levels of co-working $T a C K X$ did not result in different enzyme activity, even in highly silenced $\mathrm{T}_{2}$ plants. This might be explained by the fact that down-regulation of TaCKX1 and TaCKX11 (3) is compensated for by the up-regulation of $T a C K X 2.2, T a C K X 5$, and TaCKX9 (10), and therefore the contribution of isozymes encoded by the genes in the general pool of CKX enzyme activity is the same. Since CKX enzymes indicate different specificities for the particular cytokinin hormone [37], the cytokinin contribution and phenotypic traits of modified plants were changed accordingly, with consequent differences in the active pool of CKs influencing phenotype.

\subsection{Co-Operating Effect of TaCKX on the Level of Active CKs in Silenced Plants}

Since CKX isozymes specifically degrade CKs, the highly decreased expression of TaCKX1 and TaCKX11 (3) in 7 DAP spikes is expected to result in the observed increase of most major forms of CKs: $t Z G s, t Z$, and $c Z$ in silenced plants. We documented that both $t Z$ and $c Z$, which are isomers of zeatin, together with their derivatives are a major group of isoprenoid CKs in 7 DAP spikes. It has already been shown that trans-zeatin is the predominant form after anthesis [36,38], but comprehensive analysis of cytokinins during spike, spikelet, ovule and grain development has not yet been reported for wheat using LC-MS/MS [22]. The content of DZGs increased by $40 \%$ in silent compared to non-silent wheat plants, suggesting that this less known isoprenoid form of CKs might also play an important role in plant productivity. Interestingly, isoprenoid iP was represented in 7 DAP spikes of non-silent plants at very low quantities, but its content in 7 DAP spikes of silent plants was increased by $32 \%$. A similar relationship between the reduced expression of selected CKX family genes and cytokinin 
accumulation in reproductive organs has been observed in other species including A. thaliana [39], rice [19], and barley [25], but detailed data are not comparable to our research in wheat.

The physiological significance of these isoprenoid forms is still not very well known. $\mathrm{tZ}$ and iP, which are susceptible to CKX, were found the most abundant and bioactive CKs in maize, whereas cZ, which shows low affinity to CKX was reported to have a weak biological impact and unknown biological role $[40,41]$. However, the $\mathrm{cZ}$ concentrations changed significantly during development in maize grain, as well as in shoot and root tissues [42,43]. High levels of $c Z$ at the first developmental stage of barley spike observed by Powell et al. [44] might indicate an important role of this form in early barley embryo development, what is also documented in our results (discussed further below).

The BA is represented in 7-DAP spikes of wheat at trace amounts but their content was significantly decreased in silent plants. However, their correlations with the TaCKX genes as well as yield-related traits of non-silenced plants indicate their importance (discussed in more detail below). Interestingly, BA was found to participate in posttranscriptional and/or posttranslational regulation of protein abundance in Arabidopsis, showing high specificity to shoots and roots, and affected differential regulation of hormonal homeostasis [45].

\subsection{Cross Talk of CKs with Other Phytohormones}

Negative correlations between ABA content and TaCKX2.2 and TaCKX9 (10) expression, and positive with TaCKX11 (3), were associated with a slight decrease of ABA content in 7 DAP spikes of silenced plants. Moreover, ABA was strongly positively correlated with BA. The main auxin, IAA, remained at the same level. A ten-fold increase of GA content in silenced comparing to non-silenced plants was observed. Such cross regulation of CKs and other plant hormones is documented in other species. In maize kernels the CKX1 gene is up-regulated by cytokinin and ABA, and abiotic stress [18]. In tobacco altered cytokinin metabolism affected cytokinin, auxin, and ABA contents in leaves and chloroplasts [46], which host the highest proportion of CK-regulated proteins [47]. Moreover, auxin, $\mathrm{ABA}$ and cytokinin are involved in the hormonal control of nitrogen acquisition and signalling [48], which often limits plant growth and development. All four phytohormones, CKs, GA, IAA, and ABA, were found to be involved in the regulation of grain development in drought conditions [49]. Moreover, in shoots, BA up-regulated the abundance of proteins involved in ABA biosynthesis and the ABA response, whereas in the roots, $B A$ strongly up-regulated the majority of proteins in the ethylene biosynthetic pathway [45]. We proved that IAA, GA, and ABA contents are also co-regulated by CKs in non-silenced and silenced 7 DAP spikes. Up-regulation of major CKs and down-regulation of some minor ones in silent plants influence GA, ABA, and IAA content in a similar manner as in abiotic stress conditions.

\subsection{Coordinated Effect of TaCKX Gene Expression on the Content of CKs, Other Phytohormones and Yield-Related Traits}

Plant height in non-silenced plants is down-regulated by BA and up-regulated by IAA and GA content in the first 7 DAP spikes, resulting in taller plants. Oppositely, increased content of $t Z$ and tZGs negatively correlated with the trait in silent plants, stimulated plant height. As it was already showed $[50,51]$ and similarly to our results, plant height and root weight are regulated by CKs and IAA in opposite ways. This may be dependent on basipetal auxin flow in the stem, which suppresses axillary bud outgrowth, and similarly as in pea, auxin derived from a shoot apex suppresses the local level of CKs in the nodal stem through the regulation of CKX or IPT genes [52].

The main role in spike length seemed to be played by $\mathrm{cZ}$ and its glucoside. Increased content of CZOG in non-silenced plants negatively correlated with ABA, resulting in longer spikes. In silent plants the trait is positively regulated by $T a C K X 2.2$ together with $T a C K X 5$, and the latter is a positive regulator of enzyme activity and negative of $\mathrm{c} Z$ content. Consequently, a higher content of $\mathrm{cZ}$ in $7 \mathrm{DAP}$ spikes led to shorter spikes. CZOG, found as a positive regulator of longer spikes, is a sugar conjugate of $\mathrm{cZ}$-0-glucoside, which is the inactivated form of $\mathrm{cZ}$, showing metabolic stability against CKX 
activity [53]. Moreover, 0-glucosylation of $\mathrm{cZ}$ is catalysed by a specific 0-glucosyltransferase, cisZOG1, discovered in maize [54], and this form mainly functions in the early stages of seed development. Knowledge of function of $c Z$ degradation pathways via the CKX enzyme is limited. Interestingly, two Arabidopsis genes, $C K X 1$ and $C K X 7$, expressed in stages of active growth, were shown to have high preference for $\mathrm{CZ}$ [37]. In our case the TaCKX5 positively regulated CKX activity and negatively cZ content.

None of the tested individual TaCKX genes was involved in high TGW in non-silenced plants, but a negative correlation with $\mathrm{cZ}$ and positive with GA was found. Otherwise a significant negative correlation of TaCKX2.1 and a positive correlation of TaCKX11 (3) in determining low TGW were observed in silenced plants. Unexpectedly increased expression of the first one positively influenced $\mathrm{tZ}, \mathrm{cZ}$, and iP content and negatively GA content, and the opposite was true for the second gene, resulting in lower TGW. Therefore both TaCKX2.1 and TaCKX11 (3), acting in an opposite manner, maintain homeostasis of CKX enzyme activity and co-regulate TGW in silenced plants. A greater concentration of CKs, especially $\mathrm{tZ}$, was observed during the grain filling stage of high-yielding cultivars [44]. We might suppose that the observed higher concentrations of $t Z$ and other CKs at the 7 DAP stage, which originally was a consequence of $\mathrm{TaCKX} 1$ silencing, might accelerate germination of the grains, which resulted in smaller grains/lower TGW than in non-silenced plants. The silenced TaCKX1 co-work with down-regulated TaCKX11 (3) in increasing CK content as well as up-regulating $\mathrm{TaCKX} 2.1$, with seems to play a regulatory role. The involvement of GA in TGW and other traits demonstrated by us might be the effect of co-regulation of $C K X$ and other gibberellin-responsive genes regulating yield-related traits as well $[55,56]$. Fahy et al. [57] suggested that final grain weight might be largely determined by developmental processes prior to grain filling. This is in agreement with our observations, in which yield-related traits are differently regulated in two groups of plants, non-silent and silent. Therefore, we might suppose that the coordinated co-regulation of expression of TaCKX genes and related CKs takes place during whole plant and spike development and small seeds in silenced plants are determined at earlier stages.

Grain yield, which is very strongly correlated with grain and spike number in non-silent plants but with TGW in silent plants, is a more complex feature. Two groups of genes up-regulating or down-regulating grain yield in non-silent plants have been found. The first one includes TaCKX1, 2.2, and 5 positively regulating iP content but negatively BA. The second comprises TaCKX11 (3) acting in down-regulation of tZGs. Both groups might determine lower grain yield. It is worth to mention that TaCKX5, which is highly expressed in inflorescences and leaves might be a main player of this trait. Higher grain yield was positively regulated by enzyme activity and both, down-regulated TaCKX11 (3) as well as up-regulated TaCKX2.1 in silenced plants. Again, the TaCKX2.1 positively regulated tZGs and cZ content just like for TGW, which is rather untypical for a gene encoding a CKX enzyme degrading CKs. Therefore, the positive regulation of the main CK content by TaCKX2.1 observed by us supports its role in regulation of expression of other genes rather than encoding the CKX isozyme.

As observed in barley cultivars, changes in cytokinin form and concentration in developing kernels correspond with variation in yield [44]. Interestingly, the authors observed no peaks and no differences in CKX activity at the particular stages of spike development. This is in agreement with the homeostasis of the pool of isozymes in 7 DAP spikes of wheat, as suggested by us, which is independent of the level of silencing of TaCKX1 but is rather a consequence of co-regulation of expression of other TaCKX genes. A similar effect of increased grain yield, which was a consequence of higher spike and grain number, was obtained in barley with silenced by RNAi HvCKX1, an orthologue of TaCKX1 [20,21,25]. In this research, CKX activity was decreased, however according to Zalewski et al. [20], it was measured not in 7 DAP spikes, but in 0 DAP spikes and seedling roots. Therefore this inconsistency might be result of measurements in various organs/developmental stages. Another explanation is that these two cereal species varied three times in ploidy level, what might influence differences in action of both orthologues. The TaCKX homologues located on A, B and D chromosomes might significantly affect homeostasis of pooled CKX isozymes in wheat. Incomparable to the results obtained for RNAi silenced TaCKX1 and 
$H v C K X 1$, no changes in yield parameters were observed in mutant lines with knock-out of $H v C K X 1$ (Gasparis et al., 2019). These essential phenotypic differences between RNAi-silenced TaCKX1 and HvCKX1 or knocked out by CRISPR-Cas9 HvCKX1 might be the result of different processes involved in inactivation of the gene. The first one is regulated at the posttranscriptional and the second at the transcriptional level. Since CKs might regulate various developmental and physiological processes at the posttranscriptional level [6,7] or by modulation of context-dependent chromatin accessibility [8], the way of deactivating $\mathrm{TaCKX}$ function seemed to be important.

Spike number and grain number are highly correlated in both non-silent and silent plants and are regulated by the same groups of $\mathrm{TaCKX}$ genes as well as phytohormones. The first group includes $T a C K X 1,2.2$ and 5 positively regulating iP but negatively BA. The second comprises TaCKX11 (3) and 2.1 acting in the opposite way, and homeostasis of these hormones in non-silenced plants maintains a lower spike number. The main role in controlling higher spike and grain number in silent plants seemed to be played by $\mathrm{TaCKX} 5$, highly expressed in seedling roots, leaves, inflorescences and 0 DAP spikes. These correlations are not significant because they were measured in a stage of plant development in which the number of spikes and seed number have already been set. As reported, the higher spike number was the consequence of a higher tiller number, which was positively correlated with the content of endogenous zeatin in the field-grown wheat after exogenous hormonal application [58]. Shoot branching might also be dependent on the acropetal transport of cytokinin [52].

Root weight was positively correlated with lower expression of TaCKX9 (10) in 7 DAP spikes of non-silent plants and, negatively with increased expression of this gene in silenced plants. Therefore the gene might determine lower root weight in the first group of plants, but higher in the second. Increased expression of TaCKX9 (10) down-regulated cZOG. The same cZOG was up-regulated by TaCKX11 (3), but expression of this gene in 7 DAP spikes of silent plants is strongly decreased. Both cZ and cZOG are involved in spike length regulation as well as TGW and grain yield in the group of silenced plants. Although both tested organs are in different developmental stages, correlations between TaCKX9 (10) and TaCKX11 (3) expression in 7 DAP spikes and weight of seedling roots are reasonable. The TaCKX9 (10) is mainly expressed in younger organs from seedling roots to 0 DAP spikes and highly expressed in leaves. The TaCKX11 (3) is expressed in all organs tested [23] and both seemed to regulate seedling roots as well, although in the opposite manner. Therefore, we should take into consideration the possible action of cytokinin transport and signalling genes as well as other phytohormones which take part in hormonal crosstalk to control the regulation of root growth [59]. Accordingly, cZ type CKs found as the major forms in phloem are translocated from shoots to roots [60,61]. Some CKX genes might be induced by transcription factors [62,63], what is also observed in our unpublished yet data.

The lower plant height and higher root weight observed in the group of silenced plants of wheat is in agreement with opposed regulation of these traits by CKs and IAA mentioned above $[64,65]$. Up-regulated content of active $c Z$ in 7 DAP spikes, might influence down-regulation of this CK in roots. It has been documented that such suppressing $\mathrm{cZ}$ levels mediated by overexpression of $A t C K X 7$ affected root development in Arabidopsis [66]. A higher weight of seedling root was also obtained by silencing via RNAi or knock-out via CRISPR/Cas9 of HvCKX1 in barley plants, as in wheat, and the trait corresponded with decreased activity of CKX enzyme measured in roots (Zalewski et al., 2010; Gasparis et al., 2019).

Leaf senescence was determined in the flag leaf of the first spike by measuring chlorophyll content. Increased expression of TaCKX2.1 in silent plants up-regulated $\mathrm{tZ}$, $\mathrm{tZGs}$ and $\mathrm{cZ}$ content in 7 DAP spikes and down-regulated the trait. The gene functions in a similar way, by up-regulating these CKs in determining lower TGW and higher grain yield in silent plants. A higher content of active CKs as well as GA in 7 DAP spikes of silent plants is expected to down-regulate CKs in the flag leaves, accelerating their senescence, what is documented by the results.

It was previously demonstrated that level of chlorophyll content in flag leaves is associated with the senescence process, in which CKs suppress inhibition of senescence [67]. During this processes, proteins are degraded and nutrients are re-mobilised from senescing leaves especially to the developing 
grains [68]. We might suppose that slower spike ripening in non-silent plants, which is dependent on lower CK content in the 7 DAP spike, causes a slower flow of micronutrients as well as CKs from flag leaf to spike. Therefore, prolonged chlorophyll content in the flag leaf of the first spike negatively correlated with TGW but positively with plant height. Opposite data were obtained for flag leaves of silent plants, in which higher content of CKs in 7 DAP spikes might be the result of faster flow accelerating leaf senescence. The reduced chlorophyll content in flag leaves of the first spike of silent plants positively correlated with grain yield. The important role of $t Z$ and less active $c Z$ in the suppression of senescence was proven in maize leaves [69] and in an oat-leaf assay [37]. It was also documented that delayed senescence of wheat stay-green mutant, tasg1, at the late filling stage was related to high cytokinin and nitrogen contents [70].

\section{Materials and Methods}

\subsection{Vector Construction}

The hpRNA type of silencing cassette was constructed in pBract207 (https://www.jic.ac. $\mathrm{uk} /$ technologies/crop-transformation-bract/). It contains the Hpt selection gene under the $35 \mathrm{~S}$ promoter and cloning sites for the cloning silencing cassette under the Ubi promoter. The vector is compatible with the gateway cloning system. For cloning purposes a coding sequence of TaCKX1 (NCBI JN128583) 378 codons long was used. In the first step, the cassette was amplified using: EAC11-F: 5'-TTGAATTCGACTTCGACCGCGGCGTTTT-3' and EAC12-R: 5'-TTGAATTC ATGTCTTGGCCAGGGGAGAG-3' and cloned into the entry vector pCR8/GW/TOPO (Invitrogen). In the next step, the cassette was cloned to the destination Bract7 vector in the gateway reaction. The presence of the silencing cassette in the vector was verified by restriction analysis and sequencing. The vector was electroporated into the AGL1 strain of Agrobacterium tumefaciens and used for transformation.

\subsection{Plant Material, Agrobacterium-Mediated Transformation and In-Vitro Culture}

The spring cultivar of common wheat (Triticum aestivum L.) Kontesa was used as a donor plant for transformation experiments as well as transgenic plants. Seeds were germinated into Petri dishes for one day at $4{ }^{\circ} \mathrm{C}$ and then five days at room temperature in the dark. Six out of ten seedlings from each Petri dish were replanted into pots with soil. The plants were grown in a growth chamber under controlled environmental conditions with $20^{\circ} \mathrm{C} / 18^{\circ} \mathrm{C}$ day/night temperatures and a $16 \mathrm{~h} \mathrm{light} / 8 \mathrm{~h}$ dark photoperiod. The light intensity was $350 \mu \mathrm{mol} \cdot \mathrm{s}^{-1} \cdot \mathrm{m}^{-2}$.

Agrobacterium-mediated transformation experiments were performed according to our previously described protocols for wheat [71,72]. Putative transgenic plants were regenerated and selected on modified MS media containing $25 \mathrm{mg} \cdot \mathrm{L}^{-1}$ of hygromycin as a selectable agent.

First, 7 days after pollination, (DAP) spikes from $\mathrm{T}_{1}, \mathrm{~T}_{2}$, and control plants were collected for RT-qPCR and phytohormone quantification. Only 1 in 3 of the middle part of each spike was used for experiments (upper and lower parts were removed).

\subsection{PCR Analysis}

Genomic DNA was isolated from well-developed leaves of 14-day plants according to the modified CTAB procedure [73] or by using the KAPA3G Plant PCR Kit (Roche Sequencing and Life Science, Kapa Biosystems, Wilmington, MA, USA). The PCR for genomic DNA isolated by CTAB was carried out in a $25 \mathrm{~mL}$ reaction mixture using Platinum Taq DNA Polymerase (Invitrogen by Thermo Fisher Scientific, Waltham, MA, USA) and $120 \mathrm{ng}$ of template DNA. The reaction was run using the following program: initial denaturation step at $94{ }^{\circ} \mathrm{C}$ for $2 \mathrm{~min}, 35$ cycles of amplification at $94^{\circ} \mathrm{C}$ for $30 \mathrm{~s}, 65^{\circ} \mathrm{C}$ for $30 \mathrm{~s}, 72{ }^{\circ} \mathrm{C}$ for $30 \mathrm{~s}$ with a final extension step at $72{ }^{\circ} \mathrm{C}$ for $5 \mathrm{~min}$. The PCR for genomic DNA isolated by KAPA3G was carried out in a $50 \mu \mathrm{L}$ reaction mixture using $1 \mathrm{U}$ of KAPA3G Plant DNA Polymerase and a $0.5 \times 0.5 \mathrm{~mm}$ leaf fragment. The reaction was run using the following program: 
initial denaturation step at $95^{\circ} \mathrm{C}$ for $3 \mathrm{~min}, 40$ cycles of amplification at $95^{\circ} \mathrm{C}$ for $20 \mathrm{~s}, 68^{\circ} \mathrm{C}$ for $30 \mathrm{~s}$, $72{ }^{\circ} \mathrm{C}$ for 30 s with a final extension step at $72{ }^{\circ} \mathrm{C}$ for $2 \mathrm{~min}$.

Putative transgenic $\mathrm{T}_{0}$ and $\mathrm{T}_{1}$ plants were tested with two pairs of specific primers amplifying a fragment of the $h p t$ selection gene. The sequences of the primers for the first pair were: hygF1 5'-ATGACGCACAATCCCACTATCCT-3' and hygR1 5' $^{\prime}$-AGTTCGGTTTCAGGCAGGTCTT- ${ }^{\prime}$ ', and the amplified fragment was $405 \mathrm{bp}$. The sequences of the primers for the second pair were: hygF2 5'-GACGGCAATTTCGATGATG-3' and hygR2 5'-CCGGTCGGCATCTACTCTAT-3' , and the amplified fragment was $205 \mathrm{bp}$.

Non-transgenic null segregants were used as a control.

\subsection{RNA Extraction and $C D N A$ Synthesis}

Total RNA from 7 DAP spikes was extracted using TRI Reagent (Sigma-Aldrich, Hamburg, Germany) and 1-bromo-3-chloropropane (BCP) (AppliChem GmbH, Darmstadt, Germany) according to the manufacturer's protocol. The purity and concentration of the isolated RNA were determined using a NanoDrop spectrophotometer (NanoDrop ND-1000) and the integrity was checked by electrophoresis on $1.5 \%(\mathrm{w} / \mathrm{v})$ agarose gels. To remove the residual DNA the RNA samples were treated with DNase I, RNase-free (Thermo Fisher Scientific, Waltham, MA, USA). Each time $1 \mu \mathrm{g}$ of good quality RNA was used for cDNA synthesis using the RevertAid First Strand cDNA Synthesis Kit (Thermo Fisher Scientific) following the manufacturer's instructions. The obtained cDNA was diluted 20 times before use in RT-qPCR assays.

\subsection{Quantitative RT-qPCR}

RT-qPCR assays were performed for 6 target genes: TaCKX1 (JN128583), TaCKX2.1 (JF293079)/2.2 (FJ648070), TaCKX11 (3) (JN128585), TaCKX5 (Lei et al., 2008), TaCKX9 (10) (JN128591). Primer sequences designed for each gene as well as for the reference gene are shown in Table S1. All real-time reactions were performed in a Rotor-Gene Q (Qiagen) thermal cycler using $1 \times$ HOT FIREPol EvaGreen qPCR Mix Plus (Solis BioDyne), $0.2 \mu \mathrm{M}$ of each primer, and $4 \mu \mathrm{L}$ of 20 times diluted cDNA in a total volume of $10 \mu \mathrm{L}$. Each reaction was carried out in 3 technical replicates at the following temperature profile: $95^{\circ} \mathrm{C}-15 \mathrm{~min}$ initial denaturation and polymerase activation $\left(95^{\circ} \mathrm{C}-25 \mathrm{~s}, 62^{\circ} \mathrm{C}-25 \mathrm{~s}, 72{ }^{\circ} \mathrm{C}-25 \mathrm{~s}\right) \times$ 45 cycles, $72{ }^{\circ} \mathrm{C}-5 \mathrm{~min}$, with the melting curve at $72-99^{\circ} \mathrm{C}, 5 \mathrm{~s}$ per step. The expression of $\mathrm{TaCKX}$ genes was calculated according to the two standard curves method using ADP-ribosylation factor (Ref 2$)$ as a normalizer.

Relative expression/silencing of $\mathrm{TaCKX} 1$ was related to mean expression of the gene in non-silenced control plants set as 1.00. Relative expression of other TaCKX genes was related to each tested gene set as 1.00 in non-silenced plants.

Statistical analysis was performed using Statistica v13.3 software (StatSoft, Kraków, Poland). The normality of data distribution was tested using the Shapiro-Wilk test. To determine whether the means of two sets of data of expression levels, phytohormone concentrations, and yield-related traits between non-silenced and silenced lines are significantly different from each other (for $p$ value less than $p<0.05$ ), either the Student's $t$-test or the Mann-Whitney test was applied. Correlation coefficients were determined using parametric correlation matrices (Pearson's test) or a nonparametric correlation (Spearman's test).

\subsection{Quantification of $A B A$, Auxins, Cytokinins and $G A_{3}$}

Chemicals used for quantification were: the standard of ABA, five standards of auxins: IAA, indole-3-butyric acid (IBA), indole-3-propionic acid (IPA), 1-naphthaleneacetic acid (NAA), and 2-phenylacetic acid (PAA); twenty-seven standards of CKs: $t Z$, trans-zeatin riboside (tZR), trans-zeatin-9-glucoside (tZ9G), trans-zeatin-7-glucoside (tZ7G), trans-zeatin-O-glucoside (tZOG), trans-zeatin riboside-O-glucoside (tZROG), trans-zeatin-9-glucoside-O-glucoside (tZ9GOG), trans-zeatin-9-glucoside riboside (tZ9GR), cZ, cis-zeatin-riboside (cZR), cis-zeatin O-glucoside 
(cZOG), cis-zeatin 9-glucoside (cZ9G), cis-zeatin-O-glucoside-riboside (cZROG), dihydrozeatin (DZ), dihydrozeatin-riboside (DZR), dihydrozeatin-9-glucoside (DZ9G), dihydrozeatin-7-glucoside (DZ7G), dihydrozeatin-O-glucoside (DZOG), dihydrozeatin riboside-O-glucoside (DZROG), $N^{6}$-isopentenyladenine (iP), $N^{6}$-isopentenyladenosine (iPR), $N^{6}$-isopentenyladenosine-7-glucoside (iP7G), para-topolin $(p \mathrm{~T})$, meta-topolin $(m \mathrm{~T})$, ortho-topolin $(o \mathrm{~T})$, 6-benzylaminopurine (6-BAP), and standard of $\mathrm{GA}_{3}$.

For the measurement of phytohormones, $200 \mathrm{mg}$ of plant powders were placed into the 2-mL Eppendorf tubes, suspended in $1 \mathrm{~mL}$ of $(v / v) 50 \% \mathrm{ACN}$, and homogenized in a bead mill $(50 \mathrm{~Hz}, 5 \mathrm{~min})$ using two 5-mm tungsten balls. Then, samples were homogenized using the ultrasound processor VCX 130 (max. power $130 \mathrm{~W}$, max. frequency $20 \mathrm{kHz}, 5 \mathrm{~min}$ ) equipped with titanium probe and mixed in laboratory shaker $\left(90 \mathrm{rpm}\right.$, dark, $\left.5{ }^{\circ} \mathrm{C}, 30 \mathrm{~min}\right)$. Samples were centrifuged $(9000 \times g, 5 \mathrm{~min})$ and collected in a glass tube. For the quantification of $A B A, A X s, C K s$, and $G_{3},\left[{ }^{2} \mathrm{H}_{6}\right](+)$-cis,trans-ABA (50 ng), $\left[{ }^{2} \mathrm{H}_{5}\right]$ IAA (15 ng), $\left[{ }^{2} \mathrm{H}_{6}\right]$ iP (50 ng), $\left[{ }^{2} \mathrm{H}_{5}\right]$ tZ (30 ng), $\left[{ }^{2} \mathrm{H}_{5}\right]$-tZOG (30 ng), $\left[{ }^{2} \mathrm{H}_{3}\right]$-DZR (30 ng), and $\left[{ }^{2} \mathrm{H}_{2}\right] \mathrm{GA}_{3}(30 \mathrm{ng})$ were added to samples as internal standards.

Prepared extracts were purged using a Waters SPE Oasis HLB cartridge (Waters Corporation, Milford, MA, USA), previously activated and equilibrated using $1 \mathrm{~mL}$ of $100 \% \mathrm{MeOH}, 1 \mathrm{~mL}$ water, and $1 \mathrm{~mL}$ of $(v / v) 50 \%$ ACN [74]. Then, extracts were loaded and collected to the Eppendorf tubes and eluted with $1 \mathrm{~mL}$ of $30 \% \mathrm{ACN}(v / v)$. Samples were evaporated to dryness by centrifugal vacuum concentrator, dissolved in $50 \mu \mathrm{L}$ of $(v / v) 30 \% \mathrm{ACN}$ and transferred into the insert vials. Detection of analyzed phytohormones was performed using an Agilent 1260 Infinity series HPLC system (Agilent Technologies, Santa Clara, CA, USA) including a Q-ToF LC/MS mass spectrometer with Dual AJS ESI source; $10 \mu \mathrm{L}$ of each sample was injected on the Waters XSelect $C_{18}$ column $(250 \mathrm{~mm} \times 3.0 \mathrm{~mm}$, $5 \mu \mathrm{m})$, heated up to $50^{\circ} \mathrm{C}$. Mobile phase A was $0.01 \%(v / v)$ FA in ACN and phase B $0.01 \%(v / v)$ FA in

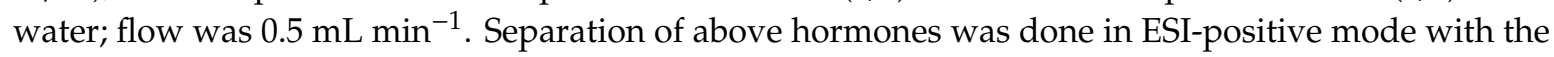
following gradient: 0-8 min flowing increased linearly from 5 to $30 \% \mathrm{~A}, 8-25 \mathrm{~min} 80 \% \mathrm{~A}, 25-28 \mathrm{~min}$ $100 \%$ A, 28-30 $\min 5 \%$ A.

For the optimization of MS/MS conditions, the chemical standards of analyzed phytohormones were directly injected to the MS in positive $\left([\mathrm{M}+\mathrm{H}]^{+}\right)$ion scan modes, then areas of detected standard peaks were calculated. $[\mathrm{M}+\mathrm{H}]^{+}$was chosen because of its significantly better signal-to-noise ratios compared to the negative ion scan modes.

Chlorophyll content was measured using an SPAD chlorophyll meter.

\section{Conclusions}

Based on the 7 DAP spike as a research object, we have documented that silencing of TaCKX1 by RNAi strongly influenced up- or down-regulation of other TaCKX genes, as well as phytohormone levels and consequently phenotype. This co-regulation is dependent on the level of silencing of the gene and is independent of cross-silencing of other TaCKX genes. Detailed analysis revealed that each tested yield-related trait is regulated by various up- or down-regulated TaCKX genes and phytohormones. Key genes involved in the regulation of grain yield, TGW, or root weight in highly silenced plants are TaCKX2.1 and TaCKX11 (3) acting antagonistically, and increased expression of the first one determines growth of $\mathrm{t} Z, \mathrm{t} Z$ derivatives, and $\mathrm{cZ}$, whereas decreased expression of the second down-regulates content of cZOG. A key role in determination of the high-yielding phenotype seemed to be played by the growing content of $\mathrm{tZ}$ in $7 \mathrm{DAP}$ spikes, which might accelerate maturation of immature grains by speeding up nutrient flow from flag leaves. This finally led to reduction of TGW but enhancement of grain number and yield. The latter traits are the result of a higher spike number, which is determined in the early stages of plant development.

Supplementary Materials: Supplementary materials can be found at http://www.mdpi.com/1422-0067/21/13/4809/ s1. Table S1: Primer sequences designed for reference gene and each of 6 tested TaCKX genes and amplicon length. Table S2: Phenotypic traits and ratio indicator in silent $\mathrm{T}_{1}$ and not silent, control plants. Table S3: Phenotypic traits and ratio indicator in silent $\mathrm{T}_{2}$ and not silent, control plants. Table S4: A. B. Correlation coefficients among 
expression of all tested TaCKX genes and enzyme activity, and phenotypic traits in not-silent (A) and highly silent $\mathrm{T}_{2}$ plants (B). * non-parametric analysis; in bold: significant at $p<0.01$.

Author Contributions: Conceptualization, A.N.-O. and W.O.; methodology, B.J., H.O., K.S., and A.B.; software, H.O. and K.S.; validation, B.J.; formal analysis, B.J.; investigation, B.J., H.O., and K.S.; data curation, B.J. and A.B.; writing —original draft preparation, A.N.-O.; writing—review and editing, A.N.-O.; visualization, A.N.-O. and H.O.; supervision, A.N.-O. and W.O.; project administration, A.N.-O.; funding acquisition, A.N.-O. All authors have read and agreed to the published version of the manuscript.

Funding: This research was funded by the National Science Centre, grant UMO-2014/13/B/NZ9/02376 and a statutory grant of PBAI-NRI.

Acknowledgments: We thank Malgorzata Wojciechowska, Izabela Skuza, Agnieszka Glowacka, Maja Boczkowska, and Agnieszka Onysk for excellent technical assistance.

Conflicts of Interest: The authors declare no conflict of interest. The funders had no role in the design of the study; in the collection, analyses, or interpretation of data; in the writing of the manuscript, or in the decision to publish the results.

\section{References}

1. Reynolds, M.; Braun, H. Wheat breeding benefits to low-input agriculture. Nat. Plants 2019, 5, 652-653. [CrossRef] [PubMed]

2. Borrill, P.; Harrington, S.A.; Uauy, C. Applying the latest advances in genomics and phenomics for trait discovery in polyploid wheat. Plant J. 2019, 97, 56-72. [CrossRef] [PubMed]

3. Nadolska-Orczyk, A.; Rajchel, I.K.; Orczyk, W.; Gasparis, S. Major genes determining yield-related traits in wheat and barley. Theor. Appl. Genet. 2017, 130, 1081-1098. [CrossRef] [PubMed]

4. Foley, J.A.; Ramankutty, N.; Brauman, K.A.; Cassidy, E.S.; Gerber, J.S.; Johnston, M.; Mueller, N.D.; O'Connell, C.; Ray, D.K.; West, P.C.; et al. Solutions for a cultivated planet. Nature 2011, 478, 337-342. [CrossRef] [PubMed]

5. Kieber, J.J.; Schaller, G.E. Cytokinin signaling in plant development. Development 2018, 478, 337-342. [CrossRef] [PubMed]

6. Kim, K.; Ryu, H.; Cho, Y.H.; Scacchi, E.; Sabatini, S.; Hwang, I. Cytokinin-facilitated proteolysis of ARABIDOPSIS RESPONSE REGULATOR 2 attenuates signaling output in two-component circuitry. Plant J. 2012, 69, 934-945. [CrossRef]

7. Cerny, M.; Dycka, F.; Bobalova, J.; Brzobohaty, B. Early cytokinin response proteins and phosphoproteins of Arabidopsis thaliana identified by proteome and phosphoproteome profiling. J. Exp. Bot. 2011, 62, 921-937. [CrossRef]

8. Potter, K.C.; Wang, J.; Schaller, G.E.; Kieber, J.J. Cytokinin modulates context-dependent chromatin accessibility through the type-B response regulators. Nat. Plants 2018, 4, 1102-1111. [CrossRef]

9. Brenner, W.G.; Ramireddy, E.; Heyl, A.; Schmulling, T. Gene regulation by cytokinin in Arabidopsis. Front. Plant Sci. 2012, 3, 8. [CrossRef]

10. Jameson, P.E.; Song, J.C. Cytokinin: A key driver of seed yield. J. Exp. Bot. 2016, 67, 593-606. [CrossRef]

11. Liu, Z.; Lv, Y.; Zhang, M.; Liu, Y.; Kong, L.; Zou, M.; Lu, G.; Cao, J.; Yu, X. Identification, expression, and comparative genomic analysis of the IPT and CKX gene families in Chinese cabbage (Brassica rapa ssp. pekinensis). BMC Genom. 2013, 14, 594. [CrossRef] [PubMed]

12. Zhang, J.; Yu, G.H.; Wen, W.W.; Ma, X.Q.; Xu, B.; Huang, B.R. Functional characterization and hormonal regulation of the PHEOPHYTINASE gene $L p P P H$ controlling leaf senescence in perennial ryegrass. J. Exp. Bot. 2016, 67, 935-945. [CrossRef] [PubMed]

13. Panda, B.B.; Sekhar, S.; Dash, S.K.; Behera, L.; Shaw, B.P. Biochemical and molecular characterisation of exogenous cytokinin application on grain filling in rice. BMC Plant Biol. 2018, 18, 89. [CrossRef] [PubMed]

14. Sakakibara, H. Cytokinins: Activity, biosynthesis, and translocation. Annu. Rev. Plant Biol. 2006, 57, 431-449. [CrossRef] [PubMed]

15. Bajguz, A.; Piotrowska, A. Conjugates of auxin and cytokinin. Phytochemistry 2009, 70, 957-969. [CrossRef]

16. Brandizzi, F. Divide, expand, differentiate-New insights on plant organ growth through cytokinin signaling. Plant J. 2019, 97, 803-804. [CrossRef]

17. Kudo, T.; Kiba, T.; Sakakibara, H. Metabolism and Long-distance Translocation of Cytokinins. J. Integr. Plant Biol. 2010, 52, 53-60. [CrossRef] 
18. Brugière, N.; Jiao, S.; Hantke, S.; Zinselmeier, C.; Roessler, J.A.; Niu, X.; Jones, R.J.; Habben, J.E. Cytokinin oxidase gene expression in maize is localized to the vasculare, and is induced by cytokinins, abscisic acid, and abiotic stress. Plant Physiol. 2003, 132, 1228-1240. [CrossRef]

19. Ashikari, M.; Sakakibara, H.; Lin, S.Y.; Yamamoto, T.; Takashi, T.; Nishimura, A.; Angeles, E.R.; Qian, Q.; Kitano, H.; Matsuoka, M. Cytokinin oxidase regulates rice grain production. Science 2005, 309, 741-745. [CrossRef]

20. Zalewski, W.; Galuszka, P.; Gasparis, S.; Orczyk, W.; Nadolska-Orczyk, A. Silencing of the HvCKX1 gene decreases the cytokinin oxidase/dehydrogenase level in barley and leads to higher plant productivity. J. Exp. Bot. 2010, 61, 1839-1851. [CrossRef]

21. Zalewski, W.; Gasparis, S.; Boczkowska, M.; Rajchel, I.K.; Kala, M.; Orczyk, W.; Nadolska-Orczyk, A. Expression patterns of $\mathrm{HvCKX}$ genes indicate their role in growth and reproductive development of barley. PLoS ONE 2014, 9, e115729. [CrossRef] [PubMed]

22. Chen, L.; Zhao, J.Q.; Song, J.C.; Jameson, P.E. Cytokinin dehydrogenase: A genetic target for yield improvement in wheat. Plant Biotechnol. J. 2020, 18, 614-630. [CrossRef]

23. Ogonowska, H.; Barchacka, K.; Gasparis, S.; Jablonski, B.; Orczyk, W.; Dmochowska-Boguta, M.; Nadolska-Orczyk, A. Specificity of expression of TaCKX family genes in developing plants of wheat and their co-operation within and among organs. PLoS ONE 2019, 14, e0214239. [CrossRef]

24. Zalewski, W.; Orczyk, W.; Gasparis, S.; Nadolska-Orczyk, A. HvCKX2 gene silencing by biolistic or Agrobacterium-mediated transformation in barley leads to different phenotypes. BMC Plant Biol. 2012, 12, 206. [CrossRef] [PubMed]

25. Holubova, K.; Hensel, G.; Vojta, P.; Tarkowski, P.; Bergougnoux, V.; Galuszka, P. Modification of barley plant productivity through regulation of cytokinin content by reverse-genetics approaches. Front. Plant Sci. 2018, 9, 1676. [CrossRef] [PubMed]

26. Li, Y.L.; Song, G.Q.; Gao, J.; Zhang, S.J.; Zhang, R.Z.; Li, W.; Chen, M.L.; Liu, M.; Xia, X.C.; Risacher, T.; et al. Enhancement of grain number per spike by RNA interference of cytokinin oxidase 2 gene in bread wheat. Hereditas 2018, 155, 33. [CrossRef] [PubMed]

27. Gasparis, S.; Przyborowski, M.; Kala, M.; Nadolska-Orczyk, A. Knockout of the HvCKX1 or HvCKX3 gene in barley (Hordeum vulgare L.) by RNA-Guided Cas9 Nuclease affects the regulation of cytokinin metabolism and root morphology. Cells 2019, 8, 782. [CrossRef]

28. Lu, J.; Chang, C.; Zhang, H.P.; Wang, S.X.; Sun, G.; Xiao, S.H.; Ma, C.X. Identification of a Novel Allele of TaCKX6a02 Associated with Grain Size, Filling Rate and Weight of Common Wheat. PLoS ONE 2015, 10, e0144765. [CrossRef] [PubMed]

29. Zhang, L.; Zhao, Y.L.; Gao, L.F.; Zhao, G.Y.; Zhou, R.H.; Zhang, B.S.; Jia, J.Z. TaCKX6-D1, the ortholog of rice OsCKX2, is associated with grain weight in hexaploid wheat. New Phytol. 2012, 195, 574-584. [CrossRef]

30. Chang, C.; Lu, J.; Zhang, H.P.; Ma, C.X.; Sun, G.L. Copy Number Variation of Cytokinin Oxidase Gene Tack 4 Associated with Grain Weight and Chlorophyll Content of Flag Leaf in Common Wheat. PLoS ONE 2015, 10, 15. [CrossRef]

31. Kersey, P.J.; Allen, J.E.; Allot, A.; Barba, M.; Boddu, S.; Bolt, B.J.; Carvalho-Silva, D.; Christensen, M.; Davis, P.; Grabmueller, C.; et al. Ensembl Genomes 2018: An integrated omics infrastructure for non-vertebrate species. Nucleic Acids Res. 2018, 46, D802-D808. [CrossRef] [PubMed]

32. Uauy, C. The high grain protein content gene $G p c-B 1$ accelerates senescence and has pleiotropic effects on protein content in wheat. J. Exp. Bot. 2006, 57, 2785-2794. [CrossRef] [PubMed]

33. Travella, S.; Klimm, T.E.; Keller, B. RNA interference-based gene silencing as an efficient tool for functional genomics in hexaploid bread wheat. Plant Physiol. 2006, 142, 6-20. [CrossRef] [PubMed]

34. Gasparis, S.; Orczyk, W.; Zalewski, W.; Nadolska-Orczyk, A. The RNA-mediated silencing of one of the Pin genes in allohexaploid wheat simultaneously decreases the expression of the other, and increases grain hardness. J. Exp. Bot. 2011, 62, 4025-4036. [CrossRef] [PubMed]

35. Gao, X.P.; Francis, D.; Ormrod, J.C.; Bennett, M.D. Changes in cell number and cell-division activity during endosperm development in allohexaploid wheat, Triticum-aestivum L. J. Exp. Bot. 1992, 43, 1603-1609. [CrossRef]

36. Hess, J.R.; Carman, J.G.; Banowetz, G.M. Hormones in wheat kernels during embryony. J. Plant Physiol. 2002, 159, 379-386. [CrossRef] 
37. Gajdosova, S.; Spichal, L.; Kaminek, M.; Hoyerova, K.; Novak, O.; Dobrev, P.I.; Galuszka, P.; Klima, P.; Gaudinova, A.; Zizkova, E.; et al. Distribution, biological activities, metabolism, and the conceivable function of cis-zeatin-type cytokinins in plants. J. Exp. Bot. 2011, 62, 2827-2840. [CrossRef]

38. Morris, R.O.; Blevins, D.G.; Dietrich, J.T.; Durley, R.C.; Gelvin, S.B.; Gray, J.; Hommes, N.G.; Kaminek, M.; Mathews, L.J.; Meilan, R.; et al. Cytokinins in plant-pathogenic bacteria and developing cereal-grains. Funct. Plant Physiol. 1993, 20, 621-637. [CrossRef]

39. Bartrina, I.; Otto, E.; Strnad, M.; Werner, T.; Schmulling, T. Cytokinin regulates the activity of reproductive meristems, flower organ size, ovule formation, and thus seed yield in Arabidopsis thaliana. Plant Cell 2011, 23, 69-80. [CrossRef]

40. Schafer, M.; Brutting, C.; Meza-Canales, I.D.; Grosskinsky, D.K.; Vankova, R.; Baldwin, I.T.; Meldau, S. The role of cis-zeatin-type cytokinins in plant growth regulation and mediating responses to environmental interactions. J. Exp. Bot. 2015, 66, 4873-4884. [CrossRef]

41. Bilyeu, K.D.; Cole, J.L.; Laskey, J.G.; Riekhof, W.R.; Esparza, T.J.; Kramer, M.D.; Morris, R.O. Molecular and biochemical characterization of a cytokinin oxidase from maize. Plant Physiol. 2001, 125, 378-386. [CrossRef] [PubMed]

42. Saleem, M.; Lamkemeyer, T.; Schutzenmeister, A.; Madlung, J.; Sakai, H.; Piepho, H.P.; Nordheim, A.; Hochholdinger, F. Specification of Cortical Parenchyma and Stele of Maize Primary Roots by Asymmetric Levels of Auxin, Cytokinin, and Cytokinin-Regulated Proteins. Plant Physiol. 2010, 152, 4-18. [CrossRef] [PubMed]

43. Zalabak, D.; Galuszka, P.; Mrizova, K.; Podlesakova, K.; Gu, R.L.; Frebortova, J. Biochemical characterization of the maize cytokinin dehydrogenase family and cytokinin profiling in developing maize plantlets in relation to the expression of cytokinin dehydrogenase genes. Plant Physiol. Biochem. 2014, 74, 283-293. [CrossRef]

44. Powell, A.E.; Paleczny, A.R.; Olechowski, H.; Emery, R.J.N. Changes in cytokinin form and concentration in developing kernels correspond with variation in yield among field-grown barley cultivars. Plant Physiol. Biochem. 2013, 64, 33-40. [CrossRef] [PubMed]

45. Zd'arska, M.; Zatloukalova, P.; Benitez, M.; Sedo, O.; Potesil, D.; Novak, O.; Svacinova, J.; Pesek, B.; Malbeck, J.; Vasickova, J.; et al. Proteome analysis in Arabidopsis reveals shoot- and root-specific targets of cytokinin action and differential regulation of hormonal homeostasis. Plant Physiol. 2013, 161, 918-930. [CrossRef]

46. Polanska, L.; Vicankova, A.; Novakova, M.; Malbeck, J.; Dobrev, P.I.; Brzobohaty, B.; Vankova, R.; Machackova, I. Altered cytokinin metabolism affects cytokinin, auxin, and abscisic acid contents in leaves and chloroplasts, and chloroplast ultrastructure in transgenic tobacco. J. Exp. Bot. 2007, 58, 637-649. [CrossRef]

47. Cerny, M.; Kuklova, A.; Hoehenwarter, W.; Fragner, L.; Novak, O.; Rotkova, G.; Jedelsky, P.L.; Zakova, K.; Smehilova, M.; Strnad, M.; et al. Proteome and metabolome profiling of cytokinin action in Arabidopsis identifying both distinct and similar responses to cytokinin down- and up-regulation. J. Exp. Bot. 2013, 64, 4193-4206. [CrossRef]

48. Kiba, T.; Kudo, T.; Kojima, M.; Sakakibara, H. Hormonal control of nitrogen acquisition: Roles of auxin, abscisic acid, and cytokinin. J. Exp. Bot. 2011, 62, 1399-1409. [CrossRef]

49. Abid, M.; Shao, Y.H.; Liu, S.X.; Wang, F.; Gao, J.W.; Jiang, D.; Tian, Z.W.; Dai, T.B. Pre-drought priming sustains grain development under post-anthesis drought stress by regulating the growth hormones in winter wheat (Triticum aestivum L.). Planta 2017, 246, 509-524. [CrossRef]

50. Perilli, S.; Moubayidin, L.; Sabatini, S. The molecular basis of cytokinin function. Curr. Opin. Plant Biol. 2010, 13, 21-26. [CrossRef]

51. Miyawaki, K.; Matsumoto-Kitano, M.; Kakimoto, T. Expression of cytokinin biosynthetic isopentenyltransferase genes in Arabidopsis: Tissue specificity and regulation by auxin, cytokinin, and nitrate. Plant J. 2004, 37, 128-138. [CrossRef] [PubMed]

52. Shimizu-Sato, S.; Tanaka, M.; Mori, H. Auxin-cytokinin interactions in the control of shoot branching. Plant Mol. Biol. 2009, 69, 429-435. [CrossRef] [PubMed]

53. Osugi, A.; Sakakibara, H. Q\&A: How do plants respond to cytokinins and what is their importance? BMC Biol. 2015, 13, 1-10. 
54. Martin, R.C.; Mok, M.C.; Habben, J.E.; Mok, D.W.S. A maize cytokinin gene encoding an O-glucosyltransferase specific to cis-zeatin. Proc. Natl. Acad. Sci. USA 2001, 98, 5922-5926. [CrossRef] [PubMed]

55. Chen, L.; Du, Y.Y.; Lu, Q.M.; Chen, H.; Meng, R.S.; Cui, C.G.; Lu, S.; Yang, Y.; Chai, Y.M.; Li, J.; et al. The Photoperiod-Insensitive Allele Ppd-D1a Promotes Earlier Flowering in Rht12 Dwarf Plants of Bread Wheat. Front. Plant Sci. 2018, 9, 1312. [CrossRef]

56. Guo, Z.F.; Liu, G.Z.; Roder, M.S.; Reif, J.C.; Ganal, M.W.; Schnurbusch, T. Genome-wide association analyses of plant growth traits during the stem elongation phase in wheat. Plant Biotechnol. J. 2018, 16, 2042-2052. [CrossRef] [PubMed]

57. Fahy, B.; Siddiqui, H.; David, L.C.; Powers, S.J.; Borrill, P.; Uauy, C.; Smith, A.M. Final grain weight is not limited by the activity of key starch-synthesising enzymes during grain filling in wheat. J. Exp. Bot. 2018, 69, 5461-5475. [CrossRef] [PubMed]

58. Cai, T.; Meng, X.P.; Liu, X.L.; Liu, T.N.; Wang, H.; Jia, Z.K.; Yang, D.Q.; Ren, X.L. Exogenous hormonal application regulates the occurrence of wheat tillers by changing endogenous hormones. Front. Plant Sci. 2018, 9, 1886. [CrossRef] [PubMed]

59. Pacifici, E.; Polverari, L.; Sabatini, S. Plant hormone cross-talk: The pivot of root growth. J. Exp. Bot. 2015, 66, 1113-1121. [CrossRef]

60. Corbesier, L.; Prinsen, E.; Jacqmard, A.; Lejeune, P.; Van Onckelen, H.; Perilleux, C.; Bernier, G. Cytokinin levels in leaves, leaf exudate and shoot apical meristem of Arabidopsis thaliana during floral transition. J. Exp. Bot. 2003, 54, 2511-2517. [CrossRef]

61. Hirose, N.; Takei, K.; Kuroha, T.; Kamada-Nobusada, T.; Hayashi, H.; Sakakibara, H. Regulation of cytokinin biosynthesis, compartmentalization and translocation. J. Exp. Bot. 2008, 59, 75-83. [CrossRef] [PubMed]

62. Reid, D.E.; Heckmann, A.B.; Novak, O.; Kelly, S.; Stougaard, J. CYTOKININ OXIDASE/DEHYDROGENASE3 Maintains Cytokinin Homeostasis during Root and Nodule Development in Lotus japonicus. Plant Physiol. 2016, 170, 1060-1074. [CrossRef] [PubMed]

63. Mao, C.J.; He, J.M.; Liu, L.N.; Deng, Q.M.; Yao, X.F.; Liu, C.M.; Qiao, Y.L.; Li, P.; Ming, F. OsNAC2 integrates auxin and cytokinin pathways to modulate rice root development. Plant Biotechnol. J. 2019, 18, 429-442. [CrossRef] [PubMed]

64. Bishopp, A.; Lehesranta, S.; Vaten, A.; Help, H.; El-Showk, S.; Scheres, B.; Helariutta, K.; Mahonen, A.P.; Sakakibara, H.; Helariutta, Y. Phloem-transported cytokinin regulates polar auxin transport and maintains vascular pattern in the root meristem. Curr. Biol. 2011, 21, 927-932. [CrossRef] [PubMed]

65. Brenner, W.G.; Schmulling, T. Transcript profiling of cytokinin action in Arabidopsis roots and shoots discovers largely similar but also organ-specific responses. BMC Plant Biol. 2012, 12, 112. [CrossRef]

66. Kollmer, I.; Novak, O.; Strnad, M.; Schmulling, T.; Werner, T. Overexpression of the cytosolic cytokinin oxidase/dehydrogenase (CKX7) from Arabidopsis causes specific changes in root growth and xylem differentiation. Plant J. 2014, 78, 359-371. [CrossRef]

67. Gan, S.S.; Amasino, R.M. Inhibition of Leaf senescence by autoregulated production of cytokinin. Science 1995, 270, 1986-1988. [CrossRef]

68. Gregersen, P.L.; Holm, P.B.; Krupinska, K. Leaf senescence and nutrient remobilisation in barley and wheat. Plant Biol. 2008, 10, 37-49. [CrossRef]

69. Behr, M.; Motyka, V.; Weihmann, F.; Malbeck, J.; Deising, H.B.; Wirsel, S.G.R. Remodeling of Cytokinin Metabolism at Infection Sites of Colletotrichum graminicola on Maize Leaves. Mol. Plant-Microbe Interact. 2012, 25, 1073-1082. [CrossRef]

70. Wang, W.Q.; Hao, Q.Q.; Wang, W.L.; Li, Q.X.; Chen, F.J.; Ni, F.; Wang, Y.; Fu, D.L.; Wu, J.J.; Wang, W. The involvement of cytokinin and nitrogen metabolism in delayed flag leaf senescence in a wheat stay-green mutant, tasg1. Plant Sci. 2019, 278, 70-79. [CrossRef]

71. Przetakiewicz, A.; Orczyk, W.; Nadolska-Orczyk, A. The effect of auxin on plant regeneration of wheat, barley and triticale. Plant Cell Tissue Organ Cult. 2003, 73, 245-256. [CrossRef]

72. Przetakiewicz, A.; Karas, A.; Orczyk, W.; Nadolska-Orczyk, A. Agrobacterium-mediated transformation of polyploid cereals. The efficiency of selection and transgene expression in wheat. Cell. Mol. Biol. Lett. 2004, 9, 903-917. [PubMed] 
73. Murray, M.G.; Thompson, W.F. Rapid Isolation of High Molecular-Weight Plant DNA. Nucleic Acids Res. 1980, 8, 4321-4325. [CrossRef] [PubMed]

74. Simura, J.; Antoniadi, I.; Siroka, J.; Tarkowska, D.; Strnad, M.; Ljung, K.; Novak, O. Plant hormonomics: Multiple phytohormone profiling by targeted metabolomics. Plant Physiol. 2018, 177, 476-489. [CrossRef] [PubMed] 